\title{
Promotion of lactation amenorrhea method intervention trial, Kazakhstan
}

Shamil Tazhibayev

Toregeldy Sharmanov

Ayan Ergalieva

Oksana Dolmatova

Orynkul Mukasheva

See next page for additional authors

Follow this and additional works at: https://knowledgecommons.popcouncil.org/departments_sbsr-rh

Part of the Demography, Population, and Ecology Commons, International Public Health Commons, Maternal and Child Health Commons, and the Women's Health Commons How does access to this work benefit you? Let us know!

\section{Recommended Citation}

Tazhibayev, Shamil, Toregeldy Sharmanov, Ayan Ergalieva, Oksana Dolmatova, Orynkul Mukasheva, Aina Seidakhmetova, and Raikhan Kushenova. 2004. "Promotion of lactation amenorrhea method intervention trial, Kazakhstan," FRONTIERS Final Report. Washington, DC: Population Council. 


\section{Authors}

Shamil Tazhibayev, Toregeldy Sharmanov, Ayan Ergalieva, Oksana Dolmatova, Orynkul Mukasheva, Aina Seidakhmetova, and Raikhan Kushenova 


\title{
Promotion of Lactation Amenorrhea Method Intervention Trial, Kazakhstan
}

\author{
Academy of Preventive Medicine, \\ Republic of Kazakhstan
}

Shamil Tazhibayev, MD, Toregeldy Sharmanov, Ayan Ergalieva, PhD, Oksana Dolmatova, PhD, Orynkul Mukasheva, PhD, Aina Seidakhmetova, and Raikhan Kushenova

May 2004

This study was funded by the U.S. AGENCY FOR INTERNATIONAL DEVELOPMENT (USAID) under the terms of Cooperative Agreement Number HRNA-00-98-00012-00 and Population Council Subcontract Number CI00.100A. The opinions expressed herein are those of the author and do not necessarily reflect the views of USAID. 


\section{EXECUTIVE SUMMARY}

\section{Background}

As a member of the Soviet Union, the Republic of Kazakhstan adopted a national policy encouraging mothers to use artificial foods in lieu of breastfeeding to enable mothers to return to the workforce soon after giving birth. This practice of lactation management, used in Kazakhstan and in other republics of the former USSR, separated newborn infants from their mothers in maternity wards, first placed infants on their mothers' breasts late after delivery and advocated feeding on a fixed schedule. Additionally, the program promoted supplementary feedings of a boiled water and glucose formula during the first days of infancy and advocated substantial supplementary feeding in the first or second months after delivery. As a result, many women lost the benefits of breastfeeding as a means of natural pregnancy prevention.

In 1997, the government reformulated its policy on breastfeeding, reversing the former norms and once again encouraging mothers to breastfeed their children under a "national program on protecting, promoting, and supporting breastfeeding." In order to expand the benefits of breastfeeding as a birth spacing option for women in the Republic of Kazakhstan, the Kazakh Academy of Nutrition at the Academy of Preventive Medicine in Almaty conducted an operations research study to test the effectiveness of Lactation Amenorrhea Method (LAM) promotion among women in Kazakhstan, as part of the Population Council's Frontiers in Reproductive Health Small Grants Program. In the Promotion of Lactation Amenorrhea Method Intervention Trial (PLAMIT), researchers trained maternity ward staff in four hospitals to provide patient counseling on the benefits of LAM as a family planning method, while five comparison hospitals received no additional support. After the intervention, they observed the breastfeeding habits of 3,969 women and 4,003 children in all nine hospitals, and conducted a total of eight interviews over 12 months with each mother. Reproductive and child health outcomes were compared according to the status of the hospital as intervention or control, and Baby-Friendly (those that are certified according to UNICEF standards) or ordinary (not Baby-Friendly). This report presents only results related to family planning.

\section{Results}

Intervention programs implemented in experimental Baby-Friendly Hospitals (BFHs) and ordinary hospitals (OHs) improved women's knowledge, skills, and desire to breastfeed. Breastfeeding indicators were significantly increased in comparison with their pre-1994 levels, and were higher in intervention hospitals than in the appropriate control hospitals. Certification of hospitals as Baby-Friendly contributed to overall improvements in breastfeeding indicators: on most indicators measured, Baby-Friendly hospitals in the control group outperformed ordinary intervention hospitals, which in turn outperformed ordinary control hospitals. Further nomination and certification of hospitals should be made to continue this success.

Knowledge of LAM as a contraceptive method was high among study participants interviewed after delivery, and 70 percent of all women reported that they planned to use LAM as protection from pregnancy. However, correct knowledge about the method remains low: only 35 percent of women knew all three criteria of effective LAM use (i.e. postpartum amenorrhea through exclusive breastfeeding for 6 months) and only 10 percent believed that working women can use

Promotion of Lactation Amenorrhea Method Intervention Trial (PLAMIT) 
LAM. Knowledge of all three criteria ranged from 61 percent in Baby-Friendly intervention hospitals to 8 percent in ordinary control hospitals. Nevertheless, at six months postpartum, the absolute numbers of LAM users and non-users were roughly equivalent $(2,391$ and 2,628 respectively) but amenorrhea rates differed dramatically, at 98 and 19 percent respectively.

Women were quite familiar with other types of family planning, in particular the IUD, oral contraceptives and condoms, which are the most commonly-used methods. Only half of all women had received family planning counseling, and 80 percent of users thought that their method was reliable. Despite this, 94 percent of women said they planned to protect themselves against a new pregnancy. Indeed, the rate of new pregnancies among observed women was quite low. The total number of women who became pregnant after the index delivery was 165, and only eight were LAM users. Six of these women delivered in control hospitals and the two others previously delivered in experimental $\mathrm{OH}$ sites. None of the woman who delivered in experimental BFHs became pregnant during the 12 month observation period and, none of the LAM users who became pregnant knew all three criteria of successful LAM use. Of all the 3,422 reported LAM users, 57 percent answered that they felt LAM provided reliable protection against a new pregnancy.

\section{Conclusions and Recommendations}

The rate of women with appropriate knowledge on key issues of LAM was low, though knowledge levels were higher among women who delivered in Baby-Friendly hospitals than in ordinary hospitals. Training activities need to be strengthened and all medical personnel should be trained to counsel women on LAM use, especially in uncertified ordinary hospitals.

The rate of LAM use and LAM efficacy is quite high, even in ordinary hospitals, in part as a result of the implementation of the national program on protecting, promoting and supporting breastfeeding. Still, both use and efficacy are higher in BFHs than in OHs, and in experimental hospitals in comparison with appropriate control hospitals, reflecting the success of the interventions implemented under the Promotion of Lactation Amenorrhea Method Intervention Trial framework in achieving success in proper LAM use. A large proportion of LAM users did not use any other contraceptive method.

Researchers also found that many mothers introduce supplementary foods too early, often beginning at three to four months after birth. One quarter of the children observed received breast milk substitutes imported from Western countries, 14 percent had formula from Commonwealth of Independent States (CIS) countries, and under four percent received non-adapted milk products prepared in local milk kitchens. Training of health personnel and women on proper implementation of supplementary feeding for breastfed children should be strengthened. 


\section{CONTENTS}

\section{Page}

Acknowledgments

Background

$\begin{array}{ll}\text { Methodology } & 7\end{array}$

$\begin{array}{ll}\text { Objectives } & 7\end{array}$

$\begin{array}{ll}\text { Study Design } & 8\end{array}$

$\begin{array}{ll}\text { Data collection and analysis } & 10\end{array}$

$\begin{array}{ll}\text { Intervention } & 11\end{array}$

$\begin{array}{ll}\text { Results } & 13\end{array}$

$\begin{array}{ll}\text { Sample Characteristics } & 13\end{array}$

Contraception: Knowledge and Use 16

$\begin{array}{ll}\text { Breastfeeding: Knowledge and Intentions } & 18\end{array}$

Lactational Amenorrhea Method Knowledge 22

Lactational Amenorrhea Method Use 25

$\begin{array}{ll}\text { Breast milk substitutes } & 29\end{array}$

Conclusions, Recommendations and Utilization 30

$\begin{array}{ll}\text { Bibliography } & 32\end{array}$ 


\section{ACKNOWLEDGEMENTS}

The Small Grants Program of Frontiers in Reproductive Health supported the PLAMIT project, and we are grateful to all the personnel in the Frontiers in Reproductive Health Program at both Tulane University and the Population Council.

We appreciate the hospitality and cooperation of all the mothers who were interviewed in maternity wards and during household visits.

Thanks to the Local Health Authorities and Health Personnel of all intervention and control hospitals who have accepted and supported the idea of the study.

We are grateful to all the hospital personnel for their collaboration and implementation of the recommendations on breastfeeding and LAM:

Perinatal Center and the Hospital for Urgent Medical Service, Aktobe City;

Maternity Hospital, Aktau City;

Perinatal Center and Maternity Hospital, Almaty City;

Maternity Hospital, Zhangaozen Town;

Rayon Central Hospital, Khromtau Town;

Rayon Central Hospital, Kazalinsk Town; and

Maternity Hospital, Aralsk Town. 


\section{BACKGROUND}

The Republic of Kazakhstan has a population of 14.8 million (2001). Just over 56 percent of the population lives in urban areas, with the remaining 44 percent inhabiting rural areas. Children under 15 years of age make up approximately one-third of the population. The life expectancy at birth is 66 years. Kazakhstan has an excellent educational system, with 99 percent of girls and boys enrolled in primary education and a literacy rate of 99.9 percent for both genders among those aged 15-24 years. Further background information is presented in Table 1 below.

Table 1. Republic of Kazakhstan National Statistics (2001)

\section{Characteristics}

Gross Domestic Product

State expenditure on social security and social assistance ( $\%$ of GDP)

State expenditure on education (\% of GDP)

State expenditure on health (\% of GDP)

Human development index (HDI)

Human development rank

Sources: Agency on Statistics, RK and UNDP 2001
US\$22.39 billion

5.7

3.2

1.9

0.773

$79^{\text {th }}$

\section{Context}

\section{Contraception and Abortion}

Induced abortion is common in Kazakhstan and accounts for 38 percent of all pregnancy outcomes (DHS 1995). Overall, 41 percent of women have had an induced abortion. Of these, 70 percent have had more than one abortion. The rate of multiple abortions increases with women's age. Among women 35 years old or older who have had an induced abortion, 78 percent have had more than one. Among these, the mean number of abortions is 3.6 per woman, and 14 percent have had six or more.

The high level of induced abortion in Kazakhstan exists in the context of moderate contraceptive use. Four out of every 10 women of reproductive age currently use a modern method (among married women, the rate is 53\%), and only one in 10 uses a traditional method. In addition, few women use Lactational Amenorrhea Method (LAM) to prevent pregnancy after childbirth. Only 1 percent of women meet the criteria for successful LAM use (i.e. a woman must be fully breastfeeding a child who is less than six months old, and she must be postpartum amenorrheic). While almost half (47\%) of infants aged 0-3 months were breastfed exclusively in 1999, the proportion was only 10 percent for children aged 4-7 months, up from three percent in 1995 (DHS 2000).

Analyses of trends in the former Soviet Union and Eastern Europe clearly demonstrate the inverse relationship between abortion and contraceptive use (e.g. Westoff 2000; Serbanescu 2004). There is clear and convincing evidence that contraception has proved to be an effective substitute for abortion in recent years in Kazakhstan, mainly due to the efforts of the National 
Family Planning Program. According to National Demographic and Health Survey (DHS) data, over an interval of five years (average for the periods 1988-89 and 1993-1995), pill and IUD prevalence rates increased by 32 percent and the abortion rate declined by 15 percent.

Preliminary, non-published data from the 1999 DHS show that the number of women using contraceptive methods has increased by 20 percent, while the abortion rate has declined by 18 percent since 1995. This is important evidence of women's willingness to use family planning methods rather than abortion to control their fertility. This operations research project examines the role that the Lactational Amenorrhea Method (LAM) plays in family planning programs in Kazakhstan.

\section{Breastfeeding and the Lactational Amenorrhea Method}

Breastfeeding is almost universal in Kazakhstan: 96 percent of children born in the three years preceding the 1995 DHS were breastfed, while the 1999 DHS found that 99 percent of children were breastfed in their first three months of life. However, less than half of children (48\%) were exclusively breastfed during these early months of infancy; most children received either plain water $(38 \%)$ or other foods and liquids $(14 \%)$ in addition to breast milk. In this age group, therefore, the "full breastfeeding" rate was 86 percent. Between the ages of four and six months, 15 percent of children were exclusively breastfed and 12 percent were breastfed and received plain water, so the "full breastfeeding" rate was 27 percent. Comparison of these two DHS surveys show that there has been very good progress in breastfeeding patterns in Kazakhstan during the last few years. This success could be used as a springboard for LAM to increase the efficacy of the nation's family planning program.

The Lactational Amenorrhea Method (LAM) is a form of contraception in which amenorrhea, due to prolonged and exclusive breastfeeding under specific circumstances, provides a period of significant, natural protection from pregnancy. Breastfeeding is thought to reduce the secretion of the gonadotropin-releasing hormone by the hypothalamus, which in turn disturbs secretion of the luteinizing hormone (LH) from the pituitary gland. Without regular, adequate LH pulses, insufficient estrogen is secreted by the ovaries to trigger ovulation, resulting in a period of infertility.

The Bellagio Consensus produced by experts at the 1988 Bellagio Conference in Italy provides the scientific rationale for the three LAM criteria:

1) postpartum amenorrhea (bleeding before the 56th day postpartum ignored),

2) first six months postpartum, and

3) full or nearly full breastfeeding. ${ }^{1}$ (Full breastfeeding signifies exclusive breastfeeding plus some supplementary water or other liquids).

When these three conditions are fulfilled, breastfeeding provides more than 98 percent protection from pregnancy in the first six months postpartum (Kennedy and Kotelchuck 1998; Kennedy et al. 1989; FHI 1988). LAM actually provides about four months of "added" protection (six

\footnotetext{
${ }^{1}$ Exclusive breastfeeding should be distinguished from "full breastfeeding" because providing the infant too much water can render LAM ineffective. When women exclusively breastfeed, LAM is an effective family planning option, whereas with early supplementation, including frequent feedings of water or other liquids, the suckling stimulation is decreased, and LAM will not be as effective.
}

Promotion of Lactation Amenorrhea Method Intervention Trial (PLAMIT) 
months minus 56 postpartum days, when new pregnancies rarely occur). Soon after the Bellagio Consensus, family planning program and policy leaders convened and dubbed the application of the Bellagio guidelines the Lactational Amenorrhea Method (Kennedy et al. 1994).

The effectiveness of LAM as a family planning method has been scientifically demonstrated. Studies of LAM in a variety of populations, including the United States, demonstrate as high as 98-100 percent effectiveness in preventing pregnancy during the first six months postpartum. There is also data to suggest that LAM can actually provide even longer protection. By 1995 , sufficient research had been conducted to warrant a follow-up conference to determine whether the original Bellagio Consensus was upheld by the studies designed to test it. The participants "concluded that the Bellagio Consensus clearly has been confirmed," according to the Consensus Statement. ${ }^{i}$ During Bellagio II, experts also considered whether the LAM criteria could or should be modified. Their Consensus Statement emphasized that the amenorrhea criterion of LAM is essential as it is an absolute reflection of ovarian quiescence. However, they concurred that the other two criteria are open to modification:

1) "It may be possible to relax the requirement of full or nearly-full breastfeeding." If relaxing full or nearly-full breastfeeding results in the diminution of the breastfeeding stimulus, then the return of fertility will be hastened. However, if women introduce supplements gradually and breastfeed exclusively before giving the infant a supplement, the breastfeeding stimulus may not be diminished.

2) "It may be possible to extend LAM beyond six months postpartum." Although the rate of pregnancy during amenorrhea rises after six months postpartum, it is still low at 12 months, ranging three to ten percent (Ramos et al. 1996; Kazi et al. 1995; Kennedy and Visness 1992; Short et al. 1991). However infants' diets must be supplemented after about six months of age, so full breastfeeding should not normally continue beyond this point. Still, if a woman is amenorrheic and maintains a high level of breastfeeding stimulation, she may realize a high level of contraceptive protection well beyond the sixth month (Kennedy and Kotelchuck 1998).

The risk of pregnancy increases at six months postpartum, when menses returns, or when breastfeeding ceases to be full or nearly full before the sixth month. As soon as one of these events occurs, consideration must be given to the adoption of another means of family planning if a high degree of protection is desired.

There is sufficient evidence to conclude that LAM is an effective contraceptive method, and is competitive in efficacy with other appropriate temporary methods (Kennedy and Kotelchuck 1998; Labbok et al. 1997; Cooney 1996). It has also been shown that even after resumption of menstruation, the probability of pregnancy is lower among women who continue to breastfeed than among women who have stopped. The data suggest that when used correctly or even if used imperfectly, LAM is a reliable way to avoid pregnancy. The fact that it is effective is an unquestionably positive attribute of LAM (Kennedy and Kotelchuck 1998). This is very important for the acceptance of LAM in national family planning programs, especially in countries where the breastfeeding rate is high and the interval between births is primarily dependent on breastfeeding where modern family planning methods are not available.

There is also evidence to suggest that LAM is not too difficult for most women

Promotion of Lactation Amenorrhea Method Intervention Trial (PLAMIT) 
to learn (e.g. Bender et al. 1998, Kennedy et al. 1998, Hight-Laukaran et al. 1997). In Ecuador, 77 percent of LAM users learned the method correctly after only one visit with a family planning worker, and 90 percent adopted the method correctly after two visits (Wade et al. 1994). Some population professionals have asserted that LAM is too difficult for women to learn and to apply (Bracher 1992, Trussell and Santow 1991) but no basis for this assertion has ever been provided. It seems logical to suppose that it would not be too difficult for most women in Kazakhstan to learn proper LAM use because of their high educational level. Almost all women of reproductive age in Kazakhstan (97\%) have had at least some education. One-third (36\%) of respondents attended primary or secondary schools, 46 percent attended secondary-special schools, and 18 percent of women have a higher education. The median number of years of schooling for women in Kazakhstan is 10 (DHS 1995).

Improved breastfeeding rates in Kazakhstan are the result of significant work to reintroduce the practice by the World Health Organization (WHO) and the United Nations Children's Fund (UNICEF) since 1993. In late 1993, four doctors from Kazakhstan were trained in Wellstart's four-week Lactation Management Education Course in San Diego, California. After the training these specialists started a Breastfeeding Training Course at the Doctors' Advanced Training Institute to prepare trainers on breastfeeding. Since 1993 more than 700 doctor trainers from all over the Republic have been trained on breastfeeding and lactation management through this course. In addition, a specialized Lactation Management Laboratory for research was established at the Institute of Nutrition in 1994. Research on breastfeeding and weaning practices, nutrition of pregnant and lactating women, and breast milk contamination was carried out in cooperation with international organizations including the WHO, UNICEF, the United Nations Development Programme (UNDP), and Wellstart in Kazakhstan and Uzbekistan in 1994-96.

Regional UNICEF and WHO offices and other appropriate establishments (research institutes, mother and child health centers, medical universities, doctors' advanced training institutes, maternity houses, and perinatal centers, among others) in Kazakhstan have collaborated to work on the national breastfeeding protecting, promoting, and supporting program. The Ministry of Health ordered a reversal of the former USSR breastfeeding practices and introduction of WHO and UNICEF recommendations as part of the public health service program. Moreover, in 1997 a Kazakhstan National Breastfeeding Policy was adopted, a working group on breastfeeding was organized, and regional Breastfeeding Coordinators were assigned in all regions of the country. The Ministry's order provides official support for work on breastfeeding and is necessary for the introduction of the 10 Steps of Successful Breastfeeding project in accordance with UNICEF's Baby-Friendly Hospital Initiative (BFHI) and WHO recommendations. Now all the work on breastfeeding in Kazakhstan has become more coordinated and centrally-oriented.

The following seven hospitals in Kazakhstan were certified as Baby-Friendly Hospitals in 1999 and all of them introduced the 10 Steps of Successful Breastfeeding into their practices.

- Republican Mother and Child Health Center, Almaty

- Almaty Perinatal Center, Almaty

- Kyzylorda Oblast Maternity Hospital, Kyzylorda Oblast

- Aralsk Rayon Maternity Hospital, Kyzylorda Oblast

Promotion of Lactation Amenorrhea Method Intervention Trial (PLAMIT) 
- Hospital and Maternity Department, Kazalinsk Central Rayon Hospital, Kyzylorda Oblast

- Karaganda Oblast Maternity Hospital, Karaganda Oblast

- Taraz Perinatal Center, Zhambyl Oblast

One might expect that the realization of the WHO/UNICEF programs to promote breastfeeding in Kazakhstan has had an essentially positive influence, not only on the rate and duration of breastfeeding and on mother and child health, but also on the duration of postpartum lactation amenorrhea. To date, however, there is a lack of evaluation data regarding whether the implementation of the BFHI in health centers positively influences the duration of postpartum lactation amenorrhea in Kazakhstan, or if it should be implemented in conjunction with other activities - for example, training medical personnel to counsel pregnant and lactating women on the use of LAM - to promote LAM use as an effective part of the national family planning program.

This operations research project was designed to answer this question and to determine reasonable ways for expanding LAM use in Kazakhstan. The need for such research was confirmed by the results of 1995 DHS: one-third of women (31\%) knew that breastfeeding reduces the risk of becoming pregnant, but many more reported that breastfeeding does not affect $(55 \%)$ or even increases $(6 \%)$ the risk of becoming pregnant. The Promotion of Lactation Amenorrhea Method Intervention Trial (PLAMIT) built on the scientific evidence supporting components of the WHO/UNICEF Baby-Friendly Hospital Initiative (BFHI) and Lactational Amenorrhea Method (LAM). The project goal was to produce research evidence linking breastfeeding to family planning through use of LAM as natural protection from pregnancy. 


\section{METHODOLOGY}

\section{Objectives}

The main goals of this research were to increase provider and client knowledge about the Lactational Amenorrheic Method (LAM) as a contraceptive option, prolong the lactational amenorrhea period, and reduce the rate of pregnancy after delivery through Lactation Management training and/or LAM training in both certified Baby-Friendly Hospitals and noncertified ordinary hospitals. The intervention provided an opportunity to expand implementation of LAM in urban and rural hospitals to promote appropriate use of the birth spacing effect of breastfeeding. The main objectives of the research were:

1) To assess the efficacy of and improve clinical guidance for LAM through a longitudinal examination and analysis of its acceptance and use, documenting:

- Acceptability, utilization, efficacy, knowledge, and satisfaction with LAM in different health care settings

- Correct LAM use, including timely acceptance of supplementary family planning after the end of LAM use

- Outcomes for clients who do not adhere to the recommended LAM guidelines

2) To evaluate possible differences between certified Baby-Friendly Hospitals versus noncertified ordinary hospitals, urban versus rural hospitals, and hospitals in western versus southern regions of the country on the following characteristics:

- rate of LAM use

- duration of lactational amenorrhea pause

- rate of new pregnancy appearance 6-12 months after delivery

3) To elaborate on the recommendations for successful implementation of Lactation Management and LAM training taking into consideration the status (certified/non-certified) and location (urban/rural) of hospitals

4) To produce evidence for the following specific issues:

- The influence of the WHO/UNICEF Baby-Friendly Hospital Initiative (BFHI) on policy and practice encouraging successful birth spacing through breastfeeding

- The influence of interventions on BFHI certified hospitals' rates of successful birth spacing through breastfeeding

- The influence of interventions on birth spacing rates of non-certified hospitals' policies and practices 


\section{Study Design}

This study used a time series design with a non-equivalent control group. Hospitals were paired by geographic region (south or west) and Baby-Friendly status (certified or non-certified). One hospital in each pair was randomly selected to receive the intervention. All women delivering in the participating facilities during a three-month period were eligible for participation.

There are two Baby-Friendly certified and five non-certified urban hospitals in Almaty City (the largest city in the country, home to approximately 10 percent of the national population). One certified and one non-certified hospital were randomly selected in Almaty City. The perinatal center was selected as the certified urban control hospital, and City Maternity \#1 was selected as the non-certified urban control hospital. Selecting these sites allowed the study team to decrease expenses for traveling and shift funds to cover the purchase of equipment necessary for conducting the fieldwork.

There were no certified Baby-Friendly Hospitals in the western region at the time of preparation of the project proposal. However one urban perinatal center in Aktobe City was certified in 2000 and purposively selected as a certified intervention hospital. One additional non-certified hospital (Maternity Department, The Hospital for Urgent Medical Service \#1) was randomly selected in Aktobe City. This allowed researchers to compare certified and non-certified hospitals located in the same city in the western region (see Table 2 below).

A special order of the National Health Agency on promoting the implementation of the PLAMIT project was sent to all city and rural hospitals. 
Table 2. Study Sites

\begin{tabular}{|c|c|c|c|c|c|c|}
\hline \multirow[b]{2}{*}{ Hospital } & \multirow[b]{2}{*}{ Region } & \multirow[b]{2}{*}{$\begin{array}{l}\text { Urban/ } \\
\text { Rural }\end{array}$} & \multirow[b]{2}{*}{$\begin{array}{l}\text { Certified } \\
\text { Baby- } \\
\text { Friendly }\end{array}$} & \multirow[b]{2}{*}{$\begin{array}{l}\text { Intervention } \\
\text { / Control }\end{array}$} & \multicolumn{2}{|c|}{ Intervention } \\
\hline & & & & & $\begin{array}{c}\text { Lactation } \\
\text { Management } \\
\text { Training* }\end{array}$ & $\begin{array}{c}\text { LAM } \\
\text { Training* }\end{array}$ \\
\hline Perinatal Center, Aktobe City & West & Urban & Yes & Intervention & - & + \\
\hline $\begin{array}{l}\text { Maternity Department, The } \\
\text { Hospital for Urgent Medical } \\
\text { Service \# 1, Aktobe City }\end{array}$ & West & Urban & No & Control & - & - \\
\hline Maternity Hospital, Aktau City & West & Urban & No & Intervention & + & + \\
\hline Perinatal Center, Almaty City & South & Urban & Yes & Control & - & - \\
\hline $\begin{array}{l}\text { Maternity Hospital \# 1, Almaty } \\
\text { City }\end{array}$ & South & Urban & No & Control & - & - \\
\hline $\begin{array}{l}\text { Maternity Hospital, Zhangaozen } \\
\text { town }\end{array}$ & West & Rural & No & Intervention & + & + \\
\hline $\begin{array}{l}\text { Maternity Department, Rayon } \\
\text { Central Hospital, Khromtau town }\end{array}$ & West & Rural & No & Control & - & - \\
\hline $\begin{array}{l}\text { Maternity Department, Rayon } \\
\text { Central Hospital, Kazalinsk town }\end{array}$ & South & Rural & Yes & Intervention & - & + \\
\hline Maternity Hospital, Aralsk town & South & Rural & Yes & Control & - & - \\
\hline
\end{tabular}

*18-hour Lactation Management training course gives knowledge mainly on breastfeeding, but does not include enough on LAM and family planning, hence the need for both Lactation Management and LAM training for non-certified intervention hospitals. Certified intervention hospitals needed only LAM training because their personnel were already trained on Lactation

Management.

\section{Timeline}

The study was executed in accordance with the project proposal, with the exception of a threemonth delay in start up.

\section{Timetable}

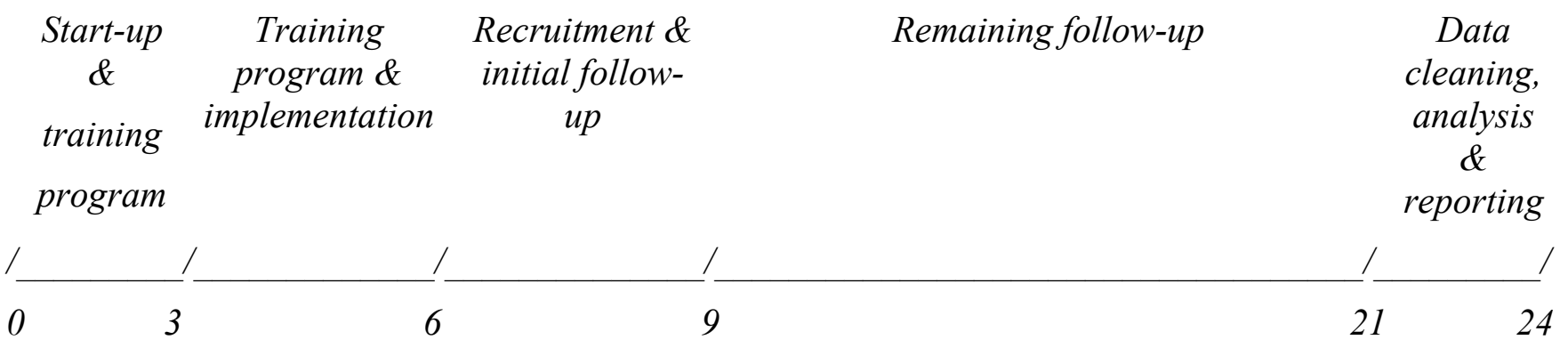

Time (months) 


\section{Data collection and analysis}

Each woman was interviewed in the hospital after delivery, and afterwards at the first, second, third, fourth, sixth, eighth, tenth, and twelfth months after delivery. Informed consent was obtained from all participants. The data collection process in households was finalized at the beginning of November 2002 when all of the children sampled were at least 12 months of age. Data on each woman's previous pregnancy was collected as well to serve as a baseline for comparison of knowledge and behavior after the index birth.

Interviewers were female medical professionals who were trained by PLAMIT staff to administer the surveys. In Almaty, interviewers at the two control hospitals worked in breastfeeding promotion prior to this study. Most held $\mathrm{PhDs}$ in epidemiology and were employees of the Kazakh Academy of Nutrition. In the other areas, most interviewers were general practice physicians. Based on previous experience, the research team expected that women would be most willing to participate in the study and its multiple interviews over a year if a relationship of trust and camaraderie was established. They encouraged interviewers to help the new mothers feel comfortable and to address any concerns they might have. Given that the surveys focused on LAM and breastfeeding, many mothers asked interviewers for advice on these topics. The research team did not feel it was ethical to deny these requests for information that could impact the health of the mother and her child. Thus it is likely that over the course of the study, women's knowledge about LAM and breastfeeding improved as a result of their participation in the surveys, apart from the impact of the intervention. However, if there was a measurable effect, it was most likely to reduce the difference between the intervention and control groups, as the most enthusiastic advocates of breastfeeding interviewed women delivering in the control hospitals in Almaty.

All the preparatory procedures needed for data collection were finalized in May 2001. A questionnaire for data collection was prepared and investigators from all the research hospitals were selected and trained for questionnaire-based data collection. Data collection was started in May in the control hospitals in Almaty City and continued in Aktobe City and the town of Khromtau in June, and in Aktau City and the town of Zhangaozen in July. Data collection in the hospitals was scheduled to take three months but the process was finalized only at the beginning of November 2001 because all the targeted hospitals were closed during the summer on a rotating basis for routine maintenance, according to customary practice.

Data entry and cleaning started in September 2002 and was finalized in January 2003. Data processing was finalized in February 2003. Because Baby-Friendly hospitals differ quite dramatically from non-certified hospitals on breastfeeding indicators, results are presented by hospital type as well as experimental status. 


\section{INTERVENTION}

The intervention consisted of training providers on lactation management, breastfeeding and the Lactation Amenorrhea Method. All of the medical personnel, including physicians, midwives, and nurses, in randomly selected intervention hospitals were trained between May-July 2001. Because providers in certified Baby-Friendly Hospitals already received Lactation Management training, medical personnel in certified intervention hospitals were trained in LAM only, while personnel in ordinary intervention hospitals received both Lactation Management and LAM training (see Table 2 above).

The following training materials were designed or expanded and distributed among medical personnel in all intervention hospitals during the Lactational Amenorrhea Method (LAM) training and counseling courses:

1) The WHO/UNICEF 18-hour training course material on breastfeeding and lactation management, including additional handouts.

2) The 20-hour training course material on LAM training and counseling, including additional handouts.

Each of the training courses has specified learning objectives, a lesson summary, and a self-test. Alternate learning activities were provided, including role-playing, case studies, discussions, pair practice, form completion, and viewing of illustrations and slides. Textbooks, articles, and teaching aids supplemented the course materials provided. Appropriate trainers for conducting both of the courses were selected and trained.

\section{Lactation Management Training}

Designed to be an integral part of achieving the long-term goal of the Baby-Friendly Hospital Initiative, an 18-hour lactation management course was developed collaboratively by staff of UNICEF, WHO, Wellstart International and Breastfeeding Support Consultants, and its Russian version was used for training of health personnel in intervention hospitals. The objectives of the course are to assist hospitals in transforming their maternity facilities into Baby-Friendly Hospital institutions that implement the "Ten Steps to Successful Breastfeeding" and to help equip them with the knowledge to make lasting policy changes. The course can not by itself transform hospitals, but it provides a common foundation for basic breastfeeding management among physicians, midwives, nurses and other maternity staff. The course consists of 14 lessons of 75 minutes each, with an additional one-hour introductory lesson. Six of the lessons include a 30minute clinical practice session. Topics covered include:

- Breastfeeding and child survival, including current recommendations

- How milk gets from breast to baby, including physiology of the breast, breast milk production and baby's suckling action

- Promoting breastfeeding during pregnancy and at birth

- Initiating breastfeeding

- Problems with breastfeeding

- Sustaining breastfeeding

- Making the community "baby-friendly"

- Making the hospital baby-friendly

Promotion of Lactation Amenorrhea Method Intervention Trial (PLAMIT) 


\section{LAM Training}

A 20-hour Lactational Amenorrhea Method training and counseling course was developed to assist hospitals to incorporate this method into their policy and practice. The course consisted of ten lessons of two hours each, with an additional one-hour introductory session. Five of the lessons include a one-hour clinical practice session. Course topics included:

- Physiology of Lactational Amenorrhea

- Bellagio Consensus of 1988 and 1995

- Benefits and limitations for mother and infant

- Acceptability, utility, efficacy and duration

- Medical contraindications

- Policy considerations for the introduction and promotion of LAM

- Family planning and LAM counseling

The Russian version of the LAM training and counseling course was elaborated by Shamil Tazhibayev and Ayan Ergalieva based on Module 7 and Module 8 on Breastfeeding and the Lactational Amenorrhea Method (LAM), Reproductive Health and Family Planning Training Curriculum:

- BREASTFEEDING AND THE LACTATIONAL AMENORRHEA METHOD OF FAMILY PLANNING. Institute for Development Training (IDT). MODULE 7 of (Training Course in Women's Health) Chapel Hill, NC: IDT, 1993.

- Comprehensive Reproductive Health and Family Planning Training Curriculum MODULE 8: BREASTFEEDING AND THE LACTATIONAL AMENORRHEA METHOD (LAM). Betty Farrell Medical Services Pathfinder International December 1997. Pathfinder International Breastfeeding and LAM Curriculum (C) 1997 Pathfinder International. 


\section{RESULTS}

\section{Socio-demographic Characteristics}

Researchers interviewed 3,969 women, including 2,862 women from urban and 1,107 from rural areas, many more than proposed in the original research design. The number of children observed was equal to 4,003 (2,890 children from urban and 1,113 from rural sites), including 17 sets of twins.

Over half of the women (57.7\%) delivered in Baby-Friendly hospitals, 34.3\% in the BFH control group and $23.4 \%$ in the BFH experimental group. The remaining $42.3 \%$ percent of women was composed of $22.2 \%$ in the ordinary hospital control group and $20.1 \%$ in the $\mathrm{OH}$ experimental group.

There were few significant differences between women delivering in the different types of hospitals. Virtually all of the sampled women were between 18 and 40 years old (98\%), and all of them were literate. Almost all (96\%) had at least a secondary education, and only 4 percent had primary or incomplete secondary education. The high level of education among interviewed women allowed researchers to expect that they were responsive to training and counseling programs on breastfeeding and LAM provided by hospital medical personnel.

The majority of women were married or in union (96\%) and lived in an apartment or private house $(92 \%)$. Very few women smoked $(2 \%)$.

More notable differences were seen in nationality, religion and income levels, as presented in Table 3. Religion and nationality are highly correlated: Kazakhs tend to be Muslim, and Russians tend to be Christian. However, both Islam and Christianity support feeding a baby by breast, so differences in religion are not expected to influence breastfeeding or LAM use. In addition, lower incomes in the sample are associated with a greater likelihood of having a summer residence or garden to grow fruits and vegetables, which can supplement income. 
Table 3. Demographic Characteristics

\begin{tabular}{|c|c|c|c|c|c|}
\hline & $\begin{array}{c}\text { BFH } \\
\text { (control) } \\
(\mathbf{n}=\mathbf{1 , 3 6 1 )} \\
\end{array}$ & $\begin{array}{c}\text { BFH } \\
\text { (intervention) } \\
(\mathbf{n}=\mathbf{9 3 0}) \\
\end{array}$ & $\begin{array}{c}\text { OH } \\
\text { (control) } \\
(\mathbf{n}=\mathbf{8 8 0}) \\
\end{array}$ & $\begin{array}{c}\mathrm{OH} \\
\text { (intervention) } \\
(\mathbf{n}=798) \\
\end{array}$ & $\begin{array}{c}\text { Total } \\
(n=3,969) \\
\end{array}$ \\
\hline \multicolumn{6}{|l|}{ Religion } \\
\hline Muslim & 61.8 & 72.3 & 63.1 & 81.5 & 68.5 \\
\hline Christian & 20.6 & 9.1 & 22.5 & 11.4 & 16.5 \\
\hline Other religion & 1.1 & 0.3 & 0.9 & 0.4 & 0.7 \\
\hline Not religious & 16.5 & 18.3 & 13.5 & 6.8 & 14.3 \\
\hline \multicolumn{6}{|l|}{ Nationality } \\
\hline Kazakh & 60.8 & 86.3 & 60.5 & 83.2 & 71.2 \\
\hline Russian & 25.4 & 8.9 & 23.5 & 10.4 & 18.1 \\
\hline Other & 13.8 & 4.7 & 16.0 & 6.4 & 10.7 \\
\hline \multicolumn{6}{|c|}{$\begin{array}{l}\text { Average monthly income } \\
\text { (per capita) }\end{array}$} \\
\hline$<=\mathrm{US} \$ 50$ & 72.5 & 94.9 & 74.2 & 67.4 & 77.1 \\
\hline$>\mathrm{US} \$ 50$ & 27.5 & 5.2 & 25.8 & 32.6 & 22.9 \\
\hline $\begin{array}{l}\text { Has summer house or } \\
\text { garden }\end{array}$ & 24.3 & 41.4 & 35.3 & 5.6 & 27.0 \\
\hline
\end{tabular}

Approximately half (53\%) of the women surveyed wanted to have more children, and about onefourth (24\%) reported that they did not want to have more children (see Table 4 below). Slightly more than one-fourth of all women had ever had an abortion, with estimates ranging from 19 to 31 percent by type of hospital. Although 51 percent of all women said they did not approve of women having abortions, 13 percent said they would have one if they had an undesired pregnancy. 
Table 4. Reproductive Characteristics

\begin{tabular}{|c|c|c|c|c|}
\hline & $\begin{array}{c}\text { BFH } \\
\text { (control) } \\
(\mathbf{n}=\mathbf{1 , 3 6 1 )} \\
\end{array}$ & $\begin{array}{c}\text { BFH } \\
\text { (intervention) } \\
(\mathbf{n}=930)\end{array}$ & $\begin{array}{c}\text { OH } \\
\text { (control) } \\
(\mathbf{n}=\mathbf{8 8 0})\end{array}$ & $\begin{array}{c}\text { OH } \\
\text { (intervention) } \\
(\mathbf{n}=798)\end{array}$ \\
\hline Attended prenatal counseling & 98.8 & 97.3 & 97.8 & 98.1 \\
\hline \multicolumn{5}{|l|}{ Want more children } \\
\hline Yes & 57.5 & 46.7 & 48.6 & 55.3 \\
\hline No & 21.2 & 23.8 & 30.8 & 21.8 \\
\hline Undecided & 19.5 & 29.6 & 20.0 & 22.2 \\
\hline Sterilized & 1.8 & 0 & 0.3 & 0.8 \\
\hline Pregnancy was desired & 96.0 & 95.7 & 95.8 & 96.7 \\
\hline Ever had an abortion & 30.4 & 19.3 & 31.4 & 23.8 \\
\hline \multicolumn{5}{|l|}{ Number of pregnancies } \\
\hline 1 & 31.8 & 36.7 & 38.5 & 30.5 \\
\hline 2 & 25.5 & 27.3 & 26.8 & 23.2 \\
\hline 3 or more & 42.7 & 36.0 & 34.6 & 46.4 \\
\hline $\begin{array}{l}\text { Number of months between deliveries } \\
\text { (among mothers with a previous child) }\end{array}$ & $(n=687)$ & $(n=503)$ & $(n=401)$ & $(n=479)$ \\
\hline$\leq 12$ & 1.2 & 2.0 & 0.7 & 1.0 \\
\hline $13-18$ & 9.3 & 12.8 & 5.7 & 11.3 \\
\hline $19-24$ & 10.5 & 13.7 & 10.1 & 16.4 \\
\hline $25-36$ & 13.5 & 18.6 & 19.7 & 16.2 \\
\hline$>36$ & 65.5 & 52.9 & 63.8 & 55.2 \\
\hline
\end{tabular}




\section{Contraception: Knowledge and Use}

General knowledge of contraceptives varied according to method and type of hospital, as shown in Table 5. Most women had heard of the more commonly-used methods, while as few as onethird knew of implants and the diaphragm. Only 50 percent of women had ever been counseled on family planning. The rate of women who were counseled was higher among those who delivered in BFHs in comparison with OHs.

Sixty-four percent of women surveyed had ever used a contraceptive. The IUD and condoms were most used; a weighted average of 31 percent reported using each of these methods. LAM was used by 20 percent and pills by 19 percent of all women interviewed. These data are consistent with the results of nationwide DHS of 1999, which found that 69 percent of women 15-49 years of age had ever used a method. Half of Kazakhstan women have ever used an IUD, 29 percent have used a condom, and 17 percent have used some form of LAM.

Only 61 percent of women knew about the advantages and disadvantages of different contraceptive methods, and 80 percent of users answered that the method of contraception they used was reliable.

Table 5. Knowledge and Ever Use of Contraceptive Methods (\%)

\begin{tabular}{|c|c|c|c|c|c|}
\hline & $\begin{array}{c}\text { BFH } \\
\text { (control) } \\
(\mathbf{n}=1,361)\end{array}$ & $\begin{array}{c}\text { BFH } \\
\text { (intervention) } \\
(\mathbf{n}=\mathbf{9 3 0})\end{array}$ & $\begin{array}{c}\text { OH } \\
\text { (control) } \\
(\mathbf{n}=\mathbf{8 8 0})\end{array}$ & $\begin{array}{c}\mathrm{OH} \\
\text { (intervention) } \\
(\mathbf{n}=798)\end{array}$ & $\begin{array}{c}\text { Total } \\
(n=3,969)\end{array}$ \\
\hline \multicolumn{6}{|l|}{ Methods Known: } \\
\hline IUD & 98.8 & 99.9 & 99.0 & 98.1 & 99.0 \\
\hline Pill & 89.7 & 93.0 & 98.6 & 91.7 & 92.9 \\
\hline Condom & 90.2 & 89.1 & 98.1 & 91.4 & 91.9 \\
\hline LAM & 81.4 & 97.3 & 79.0 & 71.3 & 82.6 \\
\hline Injectables & 81.2 & 75.1 & 88.8 & 76.6 & 80.5 \\
\hline Periodic abstinence & 74.3 & 66.1 & 88.2 & 70.5 & 74.7 \\
\hline Douche & 75.6 & 71.2 & 86.4 & 47.8 & 71.4 \\
\hline Withdrawal & 72.6 & 62.0 & 85.3 & 61.9 & 70.8 \\
\hline Female sterilization & 72.1 & 47.6 & 79.7 & 38.0 & 61.2 \\
\hline Foam/jelly & 70.2 & 47.3 & 71.9 & 40.2 & 59.2 \\
\hline Male sterilization & 67.9 & 43.7 & 69.6 & 24.8 & 53.9 \\
\hline Diaphragm & 45.8 & 25.6 & 39.8 & 7.0 & 31.9 \\
\hline Implants & 42.5 & 24.8 & 31.2 & 5.1 & 28.3 \\
\hline Ever counseled on FP & 49.6 & 68.8 & 44.9 & 36.2 & 50.4 \\
\hline $\begin{array}{l}\text { Ever used contraceptive before } \\
\text { index birth }\end{array}$ & 38.9 & 34.2 & 44.0 & 41.1 & 39.4 \\
\hline \multicolumn{6}{|c|}{ Methods ever used before index birth: } \\
\hline IUD & 30.3 & 29.8 & 27.0 & 37.4 & 30.9 \\
\hline Condom & 44.1 & 19.1 & 29.3 & 22.8 & 30.7 \\
\hline LAM & 26.3 & 26.7 & 10.3 & 13.1 & 20.2 \\
\hline Pill & 27.2 & 7.4 & 21.9 & 12.7 & 18.5 \\
\hline Periodic abstinence & 15.6 & 8.0 & 12.0 & 12.4 & 12.4 \\
\hline Douche & 13.4 & 12.2 & 9.09 & 12.9 & 12.0 \\
\hline Withdrawal & 12.7 & 3.01 & 7.6 & 13.0 & 9.4 \\
\hline Foam/jelly & 9.1 & 1.72 & 3.5 & 3.1 & 4.9 \\
\hline Injectables & 4.7 & 0.53 & 3.9 & 2.4 & 3.1 \\
\hline
\end{tabular}

Almost all women (95\%) knew a place where they could get contraceptives and 91 percent Promotion of Lactation Amenorrhea Method Intervention Trial (PLAMIT) 
reported that the price was affordable. It is important to note that 97 percent of women reported that they were planning to resume sexual intercourse after discharge from the maternity ward and 94 percent said they planned to protect against a new pregnancy.

A large proportion of women used some form of family planning during the course of the study. At two months after delivery 63 percent of women reported that they were using some protection against pregnancy and the rate ranged from 80 to 90 percent in subsequent months. The rate was higher among women who delivered in BFHs than in OHs. Only 10-20 percent of women used no protection from a new pregnancy during the twelve months of follow-up. The rate of women who used other contraceptive methods in addition to LAM is 2-5 times less than the total number of LAM users, by months after delivery. Again, this rate is higher among women who delivered in BFHs than those who delivered in OHs.

\section{Breastfeeding: Knowledge and Intentions}

Women in Kazakhstan receive information on breastfeeding from some combination of medical personnel (83\%), relatives and friends (61\%), and mass media (49\%). Other sources of information on breastfeeding are minor, totaling four percent. Some women were counseled on successful breastfeeding during antenatal visits at polyclinics $(55 \%)$ or hospital maternity departments (59\%). More women who delivered in experimental than in control hospitals had received antenatal preparation for successful breastfeeding (71\% in Baby-Friendly experimental and $61 \%$ in ordinary experimental hospitals versus $50 \%$ in Baby-Friendly control and $41 \%$ in ordinary control hospitals.)

Overall, the rate of women informed on different aspects of breastfeeding was high (80-90\%) in all the sampled hospitals. The proportion of women with knowledge, skills, and desire to breastfeed was evaluated through the following indicators:

- Knowledge of influence of breastfeeding on physical, mental, and emotional development, the immune system of the child, and mother-child bonding

- Knowledge of positive influence of colostrum on child

- Knowledge of positive influence of breastfeeding as protection against disease (e.g. diarrhea, hypotrophy, food allergy, anemia, acute respiratory infections, otitis, and others)

- Desire to room with infant

- Knowledge of positive effects of feeding on demand

- Knowledge of the duration of each feeding and number of feedings per day

- Knowledge of exclusive breastfeeding and feeding by breast at night

- Correct positioning and attachment of baby

- Knowledge of lactation management and methods to stimulate lactation

- Knowledge of benefits for lactating mother

Comparative figures on some of these indicators are shown in Table 6, below. 
Table 6. Breastfeeding Knowledge, Attitudes and Skills

\begin{tabular}{|c|c|c|c|c|}
\hline & $\begin{array}{c}\text { BFH } \\
\text { (control) }\end{array}$ & $\begin{array}{c}\text { BFH } \\
\text { (intervention) } \\
\end{array}$ & $\begin{array}{c}\mathrm{OH} \\
\text { (control) }\end{array}$ & $\begin{array}{c}\mathrm{OH} \\
\text { (intervention) } \\
\end{array}$ \\
\hline \multicolumn{5}{|l|}{ Source of breastfeeding information: } \\
\hline Medical providers & 88.8 & 91.0 & 68.4 & 80.1 \\
\hline Friends and relatives & 50.9 & 79.1 & 55.7 & 64.7 \\
\hline Media & 51.7 & 40.1 & 62.5 & 37.5 \\
\hline \multicolumn{5}{|l|}{ Agree that mother should: } \\
\hline Room in with infant & 94.6 & 94.8 & 83.3 & 85.5 \\
\hline Breastfeed on demand & 98.7 & 95.5 & 93.2 & 91.1 \\
\hline Breastfeed exclusively & 91.3 & 97.5 & 83.3 & 72.8 \\
\hline \multicolumn{5}{|l|}{ Think that breastfeeding: } \\
\hline Influences mother's health & 91.0 & 96.7 & 77.6 & 86.8 \\
\hline Decreases morbidity of mother & 97.6 & 96.0 & 91.0 & 96.9 \\
\hline Decreases morbidity of infant & 90.7 & 95.5 & 81.4 & 92.4 \\
\hline \multicolumn{5}{|l|}{ Skills } \\
\hline $\begin{array}{l}\text { Demonstrated correct position of } \\
\text { baby during breastfeeding }\end{array}$ & 94.1 & 99.1 & 90.2 & 94.7 \\
\hline Demonstrated correct attachment & 96.1 & 98.5 & 82.6 & 95.4 \\
\hline
\end{tabular}

The generally high proportion of women with knowledge, skills, and desire to breastfeed in all hospitals may be attributed to the wide-scale implementation of the Ten Steps of Successful Breastfeeding program in maternity wards, perinatal centers, polyclinics, and children's hospitals in the Republic of Kazakhstan in accordance with the 1997 national program on protecting, promoting, and supporting breastfeeding. These activities have become more effective with time, especially since 1998. The PLAMIT interventions capitalized on this knowledge to improve breastfeeding practices and train hospital staff and their patients to make use of the family planning benefits of LAM. Table 7 presents two important breastfeeding behaviors. It is standard practice in Baby-Friendly hospitals for infants to room in with their mothers unless there is a medical contraindication.

Table 7. Breastfeeding Practices

\begin{tabular}{|l|c|c|c|c|}
\hline & $\begin{array}{c}\text { BFH } \\
(\mathbf{c o n t r o l}) \\
(\mathbf{n = 1 , 3 8 5 )}\end{array}$ & $\begin{array}{c}\text { BFH } \\
\text { (intervention) } \\
(\mathbf{n = 9 3 4 )}\end{array}$ & $\begin{array}{c}\text { OH } \\
\text { (control) } \\
(\mathbf{n = 8 8 3 )}\end{array}$ & $\begin{array}{c}\text { OH } \\
\text { (intervention) } \\
(\mathbf{n = 8 0 1 )}\end{array}$ \\
\hline $\begin{array}{l}\text { Infant breastfed within 30 } \\
\text { minutes of delivery }\end{array}$ & 62.5 & 90.0 & 69.1 & 68.0 \\
\hline Infant roomed with mother & 93.1 & 96.9 & 83.2 & 82.0 \\
\hline
\end{tabular}

Breastfeeding, exclusive breastfeeding, and hypogalactia rates for preceding children were used as baseline data because they characterize women's breastfeeding status before implementation 
of the PLAMIT interventions. Over half of all women surveyed had a preceding child (52\%).

Among these women, 98 percent breastfed their previous child during infancy ( $92 \%$ exclusively), 79 percent continued to breastfeed at six months after delivery, and 51 percent breastfed their last child 12 months after delivery. Almost three-quarters (73\%) of the women used exclusive breastfeeding for their preceding child until three months after delivery, and 24 percent until six months after delivery. Proportions by type of hospital are shown in Table 8, below. One-fifth $(20 \%)$ of women with a preceding child had hypogalactia (insufficiency of breast milk) with the last child. Breastfeeding and exclusive breastfeeding rates in the experimental BFHs were higher than in control group BFHs, but this difference was not evident in ordinary hospitals.

Table 8. Breastfeeding Characteristics of Women with Previous Child and Index Child (among women who have at least one previous child)

\begin{tabular}{|c|c|c|c|c|c|c|c|c|}
\hline & \multicolumn{4}{|c|}{ Previous child } & \multicolumn{4}{|c|}{ Index child } \\
\hline Characteristic & $\begin{array}{c}\text { BFH } \\
\text { Control } \\
(n=687)\end{array}$ & $\begin{array}{c}\mathrm{BFH} \\
\text { Intervention } \\
(\mathrm{n}=503)\end{array}$ & $\begin{array}{c}\mathrm{OH} \\
\text { Control } \\
(\mathrm{n}=401)\end{array}$ & $\begin{array}{c}\mathrm{OH} \\
\text { Intervention } \\
(\mathrm{n}=479)\end{array}$ & $\begin{array}{c}\text { BFH } \\
\text { Control } \\
(n=687)\end{array}$ & $\begin{array}{c}\mathrm{BFH} \\
\text { Intervention } \\
(\mathrm{n}=503)\end{array}$ & $\begin{array}{c}\mathrm{OH} \\
\text { Control } \\
(\mathrm{n}=401)\end{array}$ & $\begin{array}{c}\mathrm{OH} \\
\text { Intervention } \\
(\mathrm{n}=479)\end{array}$ \\
\hline \multicolumn{9}{|l|}{ Breastfed } \\
\hline In hospital & 96.6 & 99.6 & 98.3 & 98.5 & 99.6 & 99.1 & 98.5 & 99.1 \\
\hline 3 months & 86.2 & 93.4 & 89.8 & 87.7 & 92.3 & 94.9 & 91.2 & 87.5 \\
\hline 6 months & 75.0 & 84.7 & 81.1 & 78.1 & 88.1 & 89.9 & 84.7 & 77.3 \\
\hline 12 months & 47.0 & 58.5 & 46.6 & 50.9 & 64.8 & 76.4 & 77.5 & 67.4 \\
\hline \multicolumn{9}{|c|}{ Breastfed exclusively } \\
\hline In hospital & 87.6 & 99.4 & 90.8 & 89.4 & 83.1 & 94.6 & 92.4 & 93.0 \\
\hline 3 months & 72.1 & 82.9 & 69.1 & 66.6 & 70.1 & 61.3 & 34.8 & 52.8 \\
\hline 6 months & 22.1 & 28.2 & 19.5 & 24.6 & 36.0 & 34.4 & 9.5 & 14.5 \\
\hline \multicolumn{9}{|l|}{ Fully breastfed } \\
\hline In hospital & no data & no data & no data & no data & 97.6 & 96.5 & 96.4 & 98.6 \\
\hline 3 months & no data & no data & no data & no data & 81.8 & 73.1 & 74.4 & 67.4 \\
\hline 6 months & no data & no data & no data & no data & 43.7 & 45.0 & 19.0 & 27.0 \\
\hline $\begin{array}{l}\text { Experienced } \\
\text { hypogalactia }\end{array}$ & 18.6 & 16.3 & 24.6 & 21.2 & $37.0 *$ & $20.0 *$ & $18.8^{*}$ & $24.2 *$ \\
\hline
\end{tabular}

* Data are available for experienced hypogalactia only among weaned up till 12 months aged children (index child) 


\section{Lactational Amenorrhea Method: Knowledge}

In the initial hospital interview, women were asked if they had ever heard of LAM at two different times: once within a series of questions about contraceptive methods, and later in the context of questions about breastfeeding and amenorrhea. While the proportions saying they "knew of" LAM differed between questions, the relative levels of each hospital remained consistent, with mothers delivering in intervention Baby-Friendly hospitals the highest (see Table 9). Women in intervention hospitals were almost three times as likely to report having been counseled on LAM use as those in the appropriate control hospitals (82\% compared to 33\% in Baby-Friendly hospitals and $41 \%$ compared to $13 \%$ in ordinary hospitals) and correspondingly they were more likely to know all three criteria for LAM use. Interestingly, in Baby-Friendly control hospitals, a greater proportion of women knew all three criteria than had been counseled, while the opposite was true in all other hospitals.

Table 9. Knowledge of LAM

\begin{tabular}{|c|c|c|c|c|}
\hline & $\begin{array}{c}\text { BFH } \\
\text { (control) }\end{array}$ & $\begin{array}{c}\text { BFH } \\
\text { (intervention) }\end{array}$ & $\begin{array}{c}\mathrm{OH} \\
\text { (control) }\end{array}$ & $\begin{array}{c}\mathrm{OH} \\
\text { (intervention) }\end{array}$ \\
\hline \multicolumn{5}{|l|}{ Have heard of LAM } \\
\hline In contraceptive section & 81.4 & 97.3 & 79.0 & 71.3 \\
\hline In breastfeeding section & 70.2 & 84.7 & 42.6 & 58.8 \\
\hline Had been counseled in LAM & 33.1 & 81.8 & 13.0 & 40.4 \\
\hline \multicolumn{5}{|l|}{ LAM criteria known: } \\
\hline 3 & 40.3 & 60.8 & 7.7 & 27.4 \\
\hline 2 & 29.0 & 13.2 & 14.6 & 33.1 \\
\hline 1 & 15.5 & 14.0 & 47.4 & 37.5 \\
\hline 0 & 9.6 & 1.8 & 16.8 & 3.9 \\
\hline Intend to use LAM & 81.3 & 76.2 & 47.8 & 66.7 \\
\hline
\end{tabular}

The PLAMIT training improved women's knowledge on the criteria of effective LAM use, but the overall rate of women who could cite all three criteria (i.e. exclusive breast feeding, first six months postpartum, and amenorrhea) remained low at 35 percent overall. After the intervention, 61 percent of women in the experimental BFH sites knew all three criteria for effective use, and only 2 percent knew none of the requirements. By comparison, 40 percent of women in the control BFHs knew all three, and 10 percent knew of none. Similarly, 27 percent of experimental $\mathrm{OH}$ patients knew all three, and only 4 percent knew none, while only 8 percent of $\mathrm{OH}$ control site patients knew all three, and 17 percent did not know any.

Women are familiar with many of the factors that contribute to effective LAM use, and results indicate that they simply require proper counseling for a complete understanding of how the method works. Women understand the principles of lactational amenorrhea as protection against a subsequent pregnancy. Overall, three-quarters knew that breastfeeding increases the duration of lactational amenorrhea, and 84 percent knew that lactational amenorrhea decreases the probability of becoming pregnant. Over half knew they were more likely to become pregnant after six months or longer postpartum. As with other indicators, knowledge was greatest among women delivering at Baby-Friendly intervention hospitals and lowest among women delivering at ordinary control hospitals (see Figure 1).

Promotion of Lactation Amenorrhea Method Intervention Trial (PLAMIT) 


\section{Figure 1. Lactational Amenorrhea Knowledge}

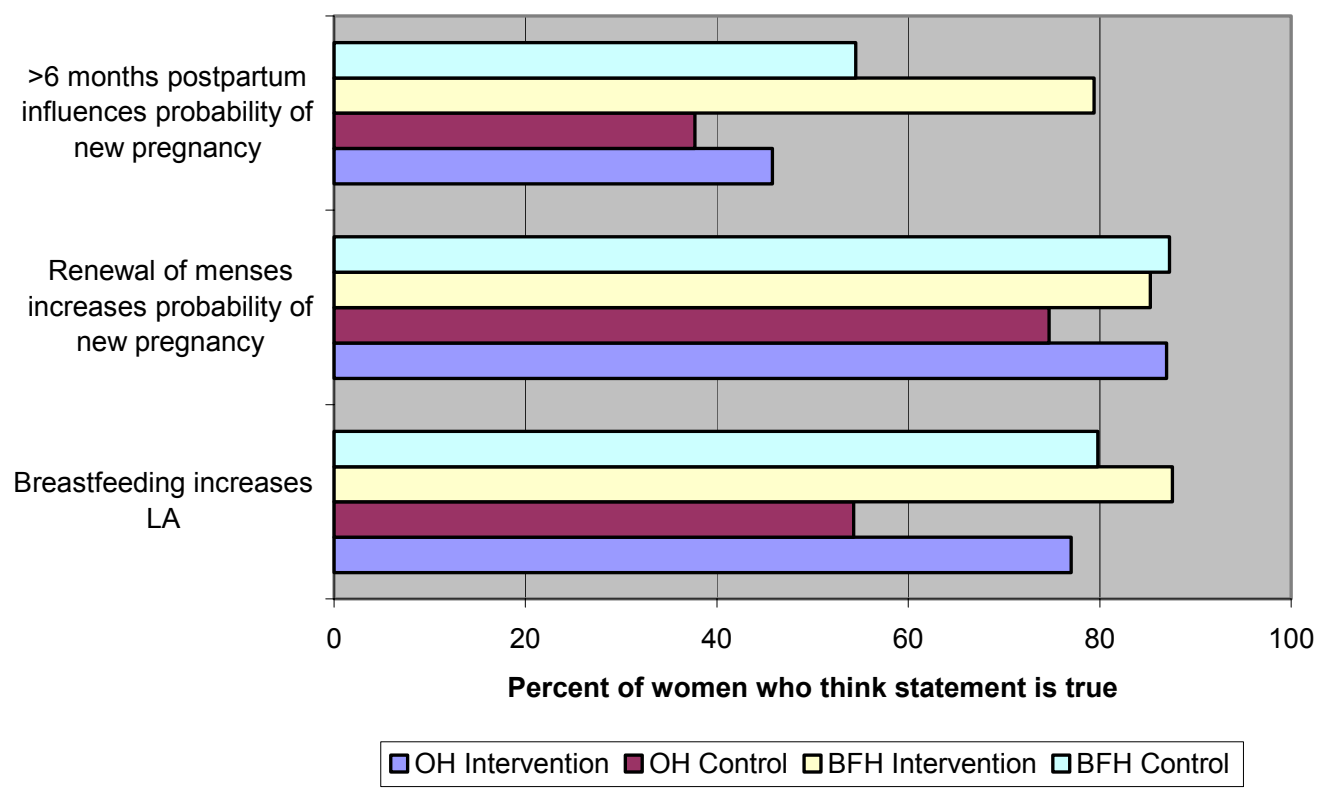

In addition to being asked for the three specific criteria for LAM, women were asked various questions about how different behaviors affect LAM, such as the frequency and duration of feedings, and feeding at night. More than three-quarters of women in Baby-Friendly intervention hospitals answered correctly on all of these questions, compared to roughly two-thirds in BabyFriendly control hospitals, half in ordinary intervention hospitals and approximately one quarter in ordinary control hospitals. Relative levels of knowledge are illustrated in Figure 2 below.

\section{Figure 2. LAM Efficiency Knowledge}

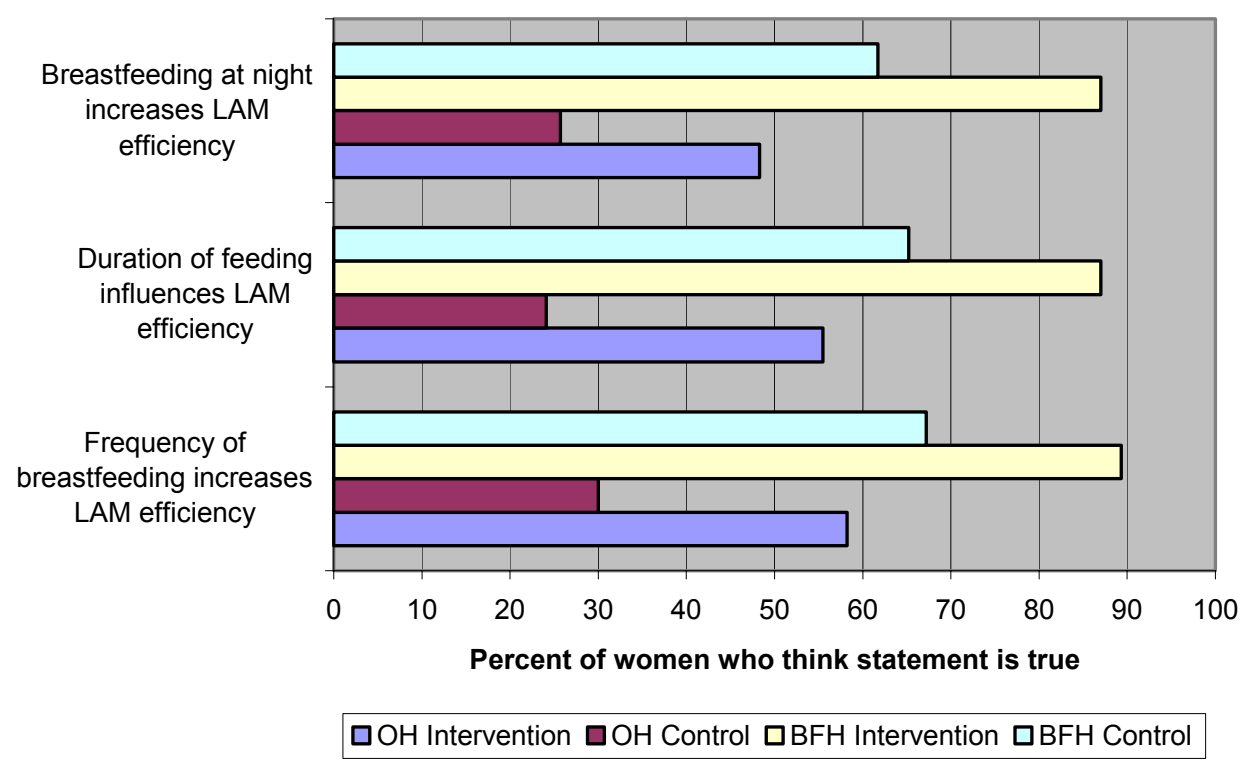

Knowledge about when to replace or supplement LAM with another family planning method was lower and more varied. Most women recognized that the return of menstruation signaled the 
need for a new method, while fewer know that introducing supplementary foods to their infants diet did (see Figure 3).

\section{Figure 3. Supplementary Contraception Knowledge}

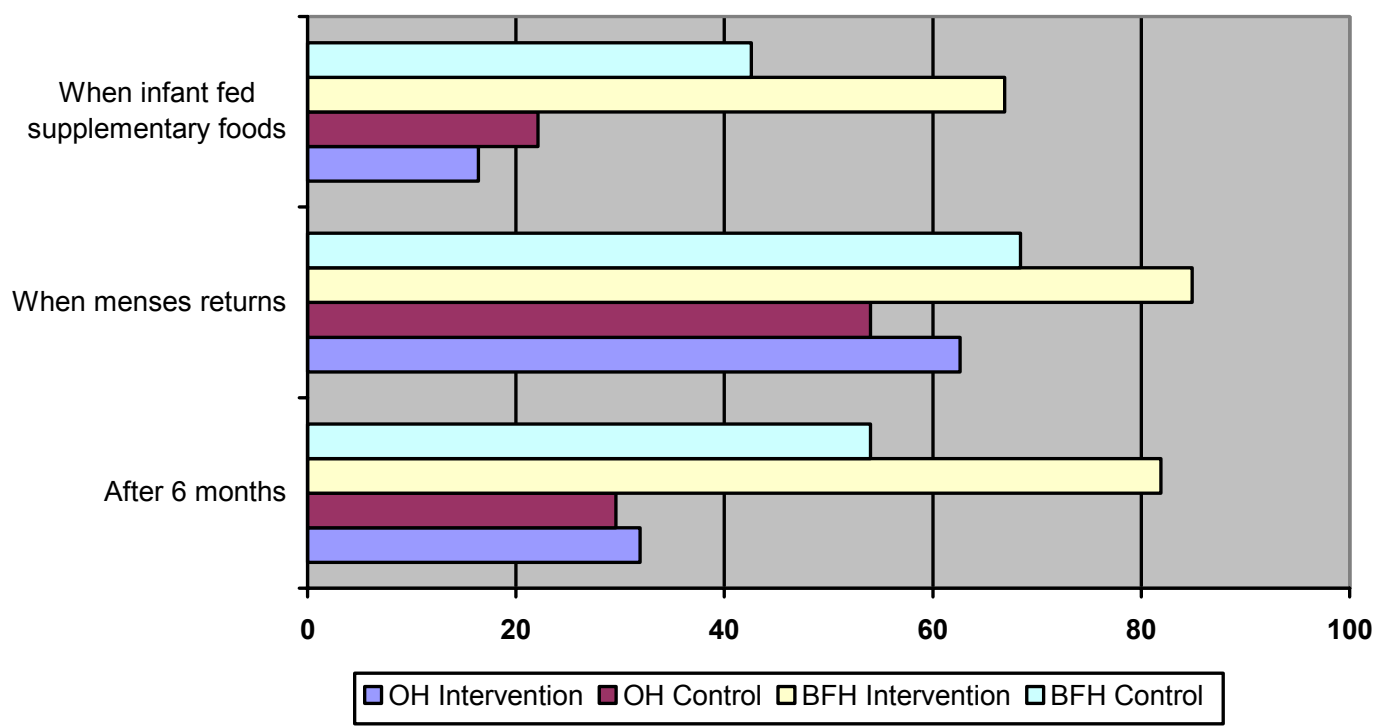

Few women in either the experimental or control sites knew that LAM can be used by working women. Still, twice as many women in the experimental BFHs felt that working women could use the method than women in the control site (20 versus $9 \%$ ). In the ordinary hospitals, 10 percent of intervention clients believed working women could use LAM, compared to 2 percent in the control.

\section{Lactational Amenorrhea Method: Use}

Notably, many more women reported they intended to use LAM at the initial interview than knew all three criteria (see Figure 4, below). One possible explanation is that in the course of the interview, women learned more about LAM, either from staff, interviewers, or even other mothers who were aware of LAM. This is possible, as the interviewers were instructed to answer any questions the women had, and may have done so during rather than after the interview. Another possibility is that some positive responses were the result of a courtesy bias on the part of the new mothers. Particularly in Baby-Friendly hospitals, it is quite clear that breastfeeding is recommended and expected; there are no facilities for substitute feeding by healthy mothers. Women may have felt they were expected to use LAM, and said they intended to. Indeed, rates of LAM use at one month (see Table 10) indicate that few of these women acted on their stated intentions to use LAM. Overall 5 percent of women reported LAM use during the first month (range of 0.5 to $9.8 \%$ ) and 78 percent said they were LAM users at three months (range of 73.5 to $81.4 \%)$. 
Figure 4. Women who said they intended to use LAM and women who knew all three criteria for LAM use

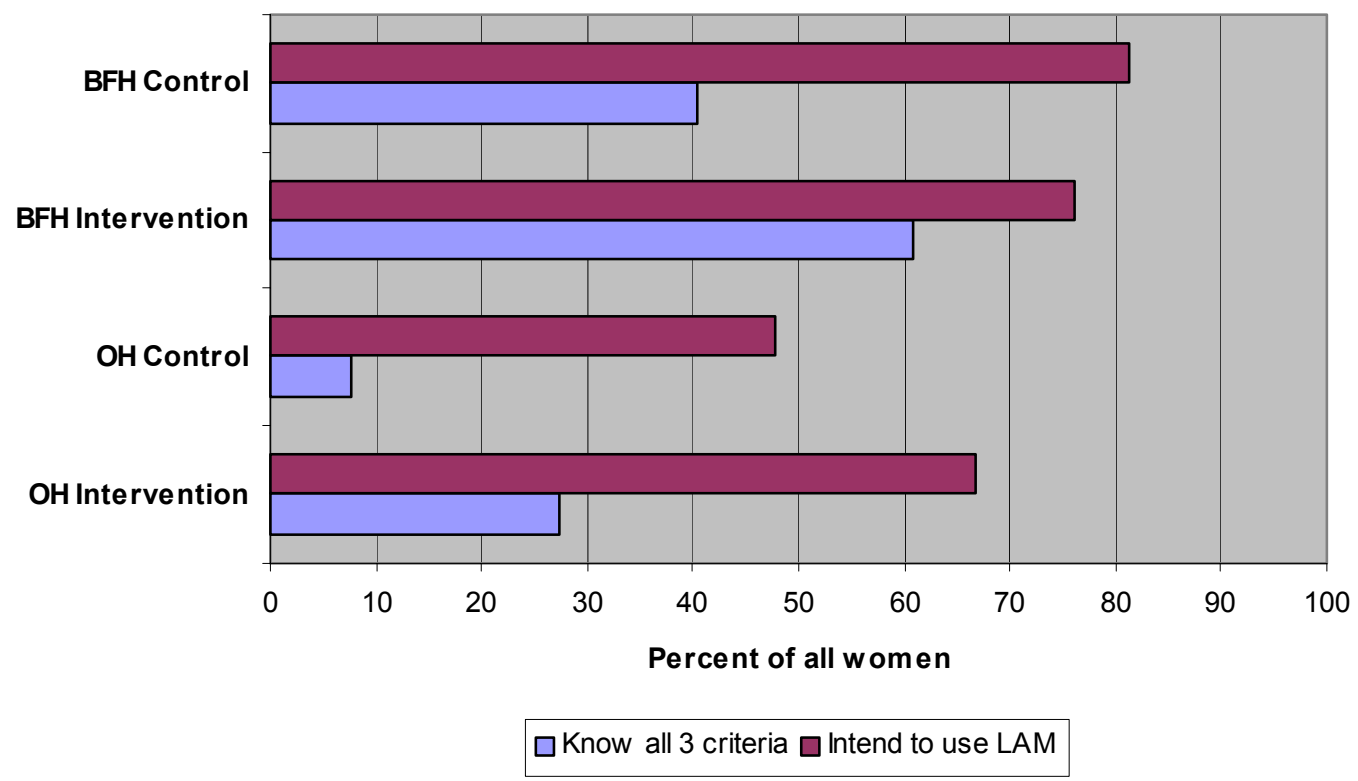

Reported LAM use increased in the second and third months, possibly because women decided to adopt the method and their menstruation had not yet returned. Because almost all women are amenorrheic for the first month postpartum, and many women in the sample were breastfeeding fully, it is possible for a woman to begin using LAM in the second or even third month. Ideally, however, LAM use should begin in the first month, and the greater the delay, the less effective it is likely to be. Eighty-one percent of women who delivered in both the intervention and control BFHs reported LAM use at three months postpartum, compared to about 74 percent in the OHs. Table 10 shows reported rates of LAM use by months after delivery.

Table 10. Reported LAM use by months postpartum

\begin{tabular}{|c|c|c|c|c|}
\hline Months & $\begin{array}{c}\mathrm{BFH} \\
\text { Control } \\
(\mathrm{n}=1,361)\end{array}$ & $\begin{array}{c}\mathrm{BFH} \\
\text { Intervention } \\
(\mathrm{n}=930)\end{array}$ & $\begin{array}{c}\mathrm{OH} \\
\text { Control } \\
(\mathrm{n}=880)\end{array}$ & $\begin{array}{c}\mathrm{OH} \\
\text { Intervention } \\
(\mathrm{n}=798)\end{array}$ \\
\hline 1 & 9.8 & 0.5 & 1.0 & 4.3 \\
\hline 2 & 65.3 & 54.9 & 68.0 & 55.0 \\
\hline 3 & 81.4 & 80.9 & 73.5 & 74.4 \\
\hline 6 & 66.4 & 65.1 & 52.4 & 52.9 \\
\hline 9 & 37.0 & 43.3 & 24.0 & 26.9 \\
\hline 12 & 21.3 & 27.4 & 13.8 & 12.9 \\
\hline
\end{tabular}

The reported rates of LAM use did not differ greatly between experimental and control hospitals of the same type, but there were substantial differences when only women who knew all three criteria and were amenorrheic were compared. The rate of women who used LAM, knew all three criteria of effective LAM use and were effectively using it (i.e. hadn't experienced a return 
of menstruation) is much lower than the rate of all reported LAM use, as can be seen in Figure 5 (Baby-Friendly Hospitals) and Figure 6 (Ordinary Hospitals). The rates were much higher among women who delivered in BFHs than in $\mathrm{OHs}$, and among women who delivered in experimental hospitals than in appropriate control hospitals.

Figure 5. Women who used LAM vs. women who used LAM, knew all 3 criteria and were amenorrheic, Baby-Friendly Hospitals

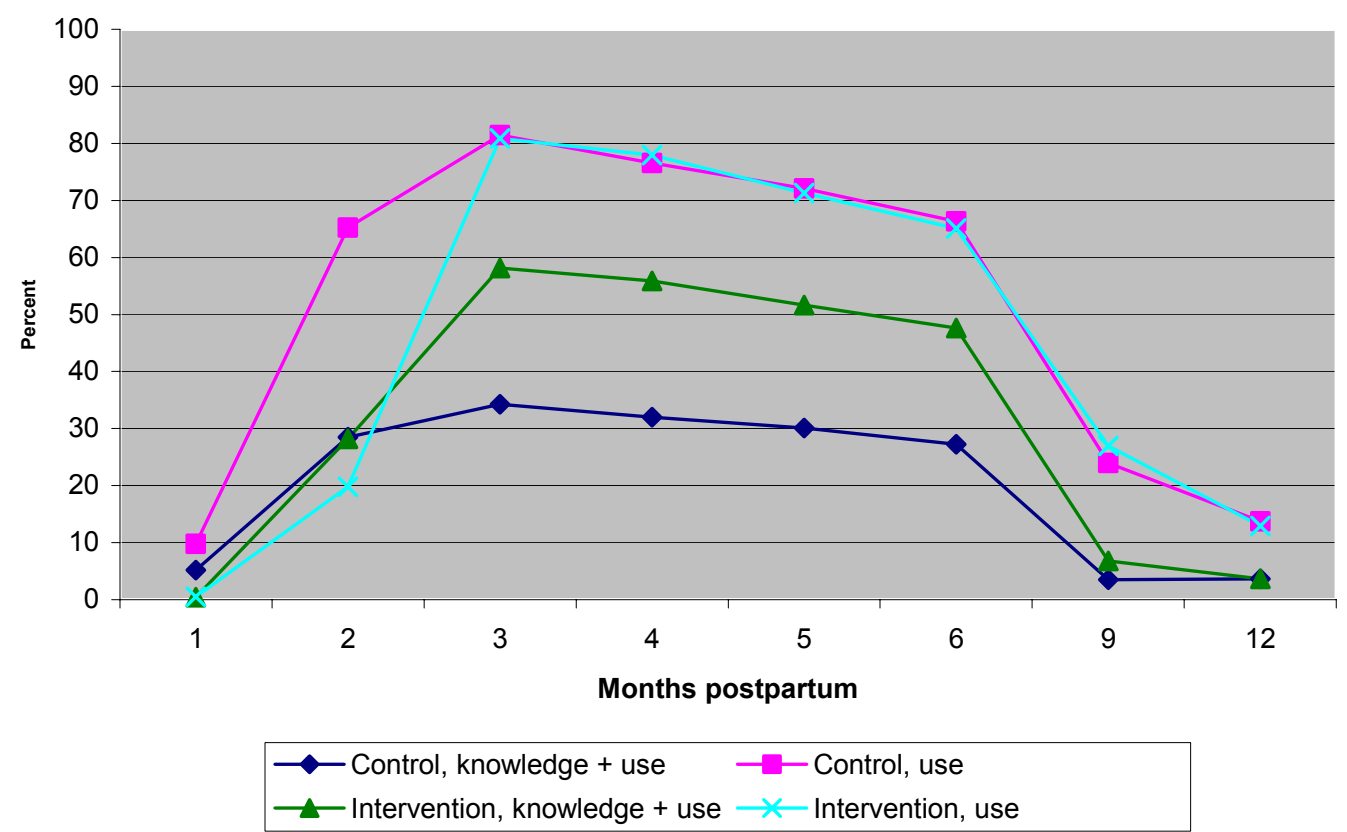

Figure 6. Women who used LAM vs. women who used LAM, knew all 3 criteria and were amenorrheic, Ordinary Hospitals

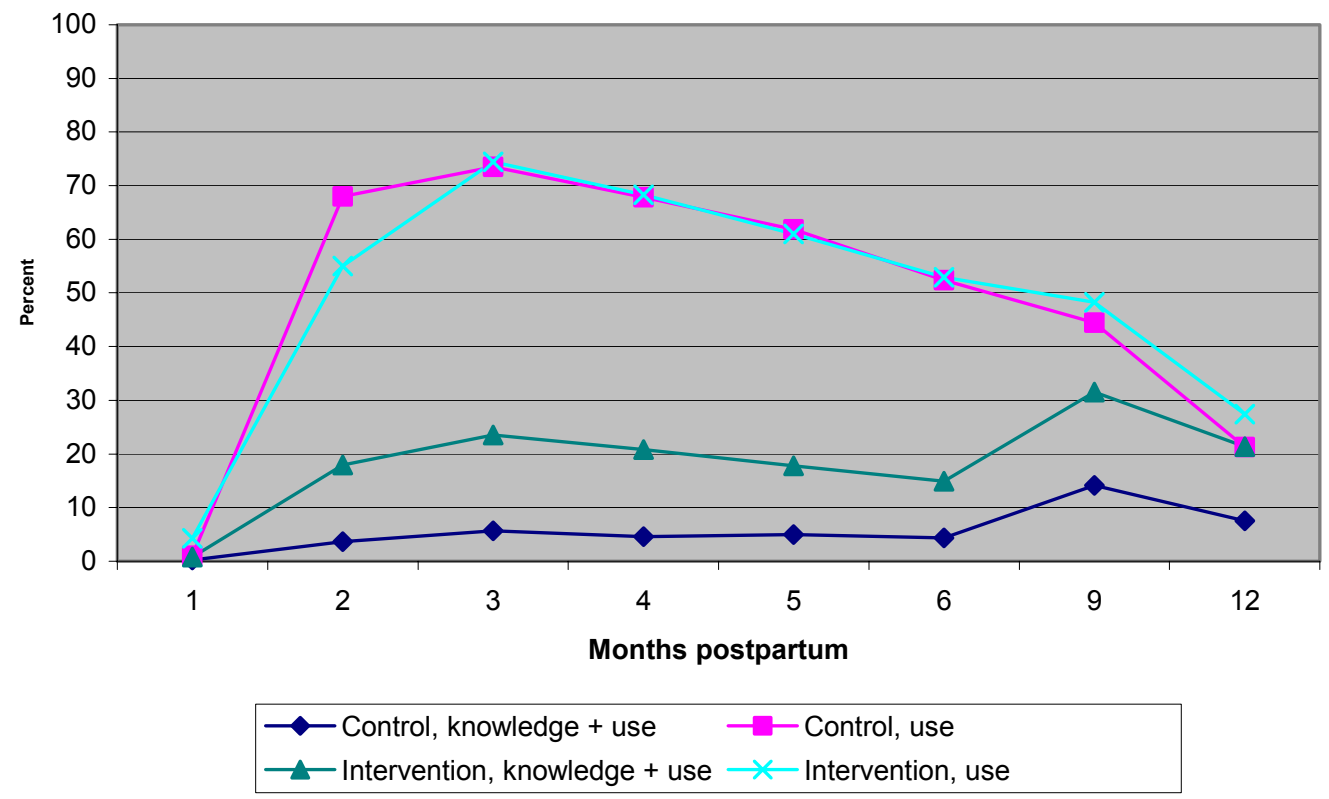

Promotion of Lactation Amenorrhea Method Intervention Trial (PLAMIT) 
Three months after delivery, the majority of LAM users remained amenorrheic (see Table 11 and Figure 7 below) and this proportion declined only slightly throughout the study period. This is in part because amenorrhea is necessary for correct LAM use; hence, women who begin menstruating drop out of the pool of LAM users. Nevertheless, at six months postpartum, the absolute numbers of LAM users and non-users were roughly equivalent (2391 and 2628 respectively) but amenorrhea rates differed dramatically, at 98 percent and 19 percent respectively.

Table 11. Amenorrhea by months postpartum among LAM users and non-users

\begin{tabular}{cccccccccc} 
Month & $\begin{array}{c}\text { LAM } \\
\text { Users }\end{array}$ & $\begin{array}{c}\text { Remained } \\
\text { Amenorrheic }\end{array}$ & $\%$ & $\begin{array}{c}\text { Non- } \\
\text { LAM } \\
\text { Users }\end{array}$ & $\begin{array}{c}\text { Remained } \\
\text { Amenorrheic }\end{array}$ & $\%$ & $\begin{array}{c}\text { Total } \\
\text { Amenorrheic }\end{array}$ & $\begin{array}{c}\text { \% of Total } \\
(\mathrm{n}=3,969)\end{array}$ & $\begin{array}{c}\% \\
\text { LAM } \\
\text { Users }\end{array}$ \\
\hline 1 & 181 & 180 & 99.4 & 3,788 & 3,774 & 99.6 & 3,954 & 99.6 & 5.5 \\
2 & 2,285 & 2,253 & 98.6 & 1,684 & 1,448 & 86.0 & 3,701 & 93.2 & 60.9 \\
3 & 3,101 & 3,064 & 98.8 & 868 & 353 & 40.7 & 3,417 & 86.1 & 89.7 \\
6 & 2,391 & 2,332 & 97.5 & 1,578 & 296 & 18.8 & 2,628 & 66.2 & 88.7 \\
9 & 1,333 & 1,295 & 97.1 & 2,636 & 389 & 14.8 & 1,684 & 42.4 & 76.9 \\
12 & 769 & 730 & 94.9 & 3,200 & 446 & 13.9 & 1,176 & 29.6 & 62.1
\end{tabular}

\section{Figure 7. Percentage of LAM users and non-users remaining amenorrheic, by month} postpartum

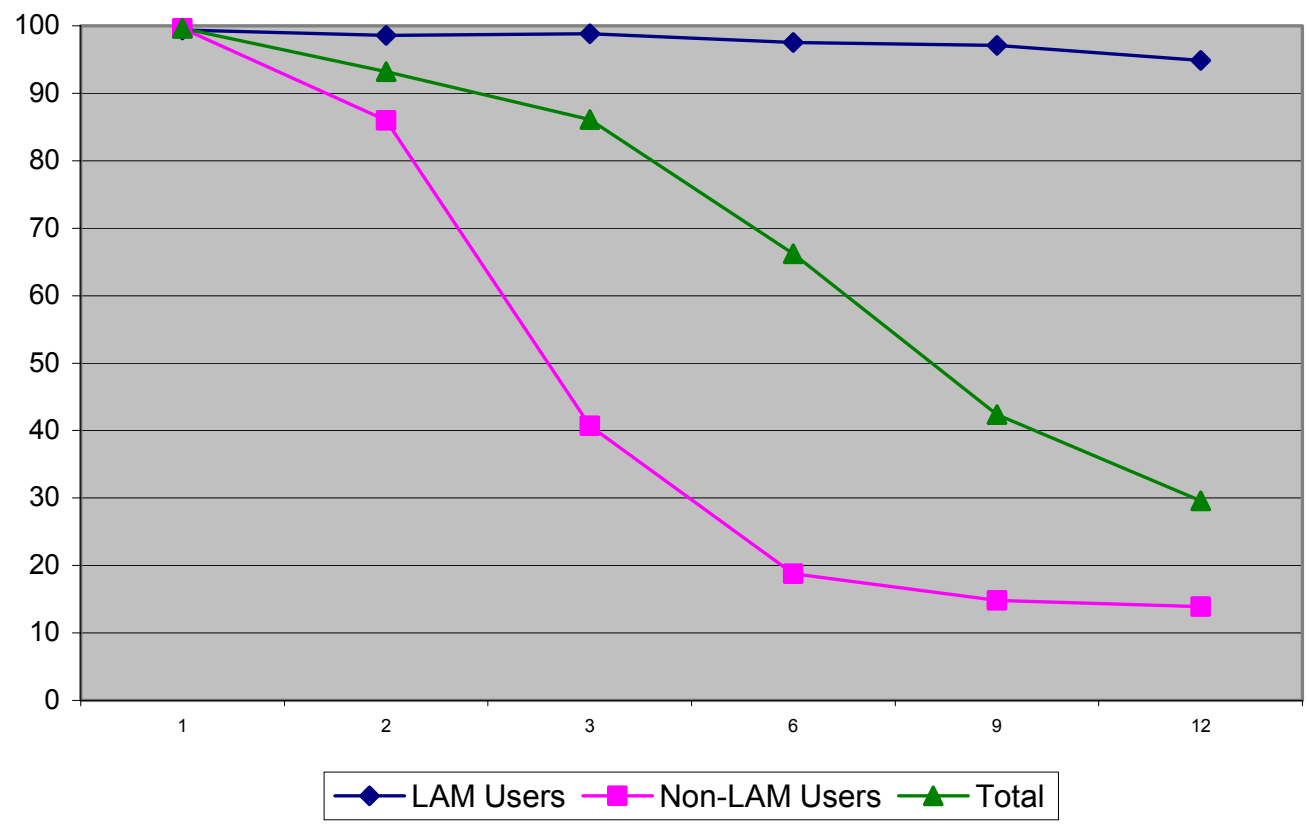

A major proportion of LAM users are women who did not use any other contraceptive method. However, among women who did not use LAM, the rate of those who adopted another family planning method gradually increased by months after delivery. At four months, 11 percent of non-LAM users from all groups were using another method, and at 12 months, 56 percent of 
women not using LAM were using another method. Contrary to most results, the proportion of women using family planning methods other than LAM was higher at OHs than at BFHs, as shown in Figure 8, below.

\section{Figure 8. Women who did not use LAM but used another contraceptive method, by month postpartum}

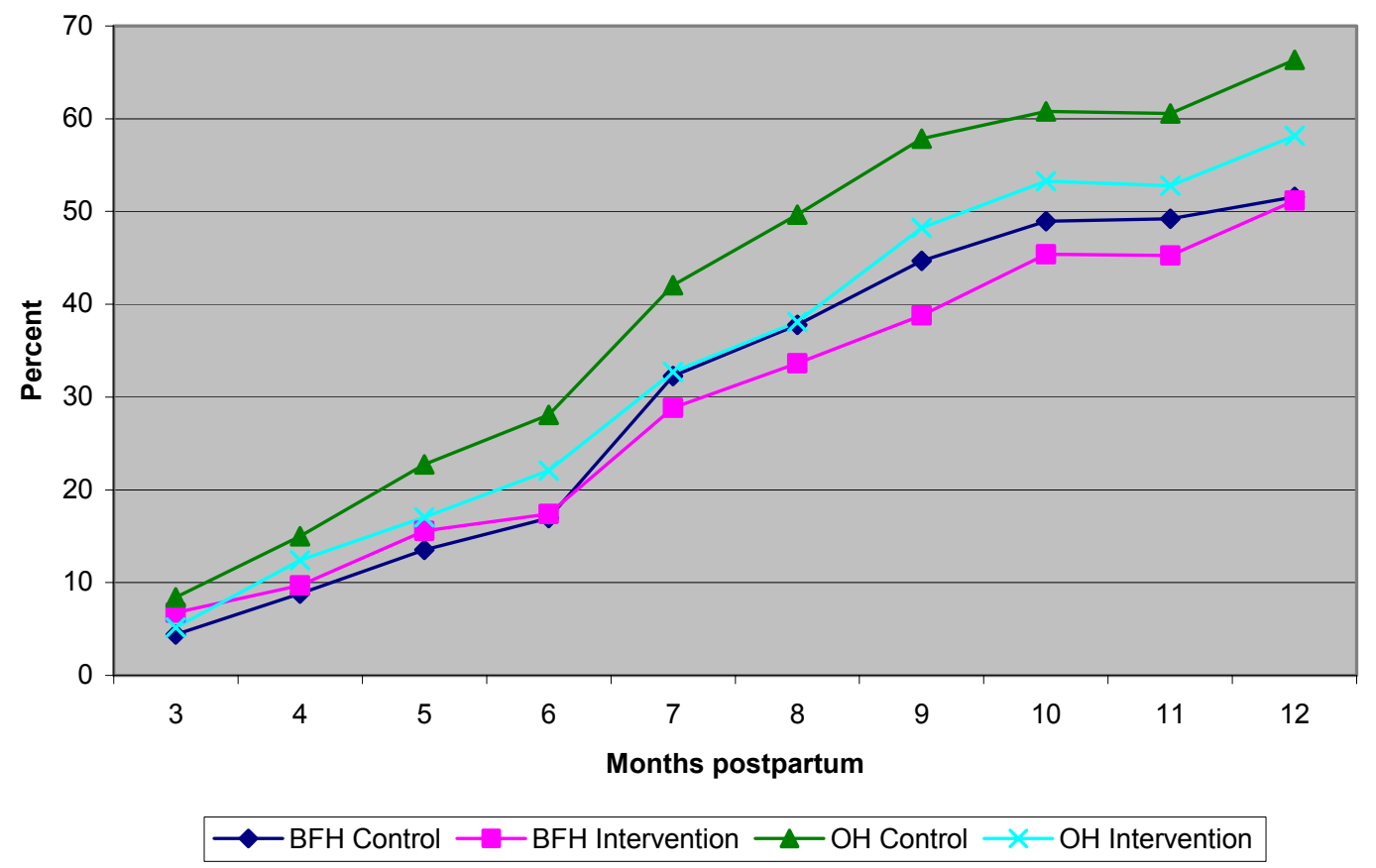

Regardless of contraceptive use, the rate of new pregnancies among observed women was quite low, between 0.05 and 0.76 percent, depending on the number of months after delivery. The total number of women who became pregnant after the index delivery is 165 , and only eight of them were LAM users. Six of these women had delivered in control hospitals and the two others delivered in experimental $\mathrm{OH}$ sites. None of the woman who delivered in experimental BFHs became pregnant during the 12 month observation period and none of the LAM users who became pregnant knew all three criteria of successful LAM use. Just over half of all women who used LAM at any point during the study $(3,422)$ said that they felt LAM provided reliable protection against a new pregnancy. A very small percentage of women $(1.56 \%)$ reported having abortions during the 12 month observation period. 


\section{Breast milk substitute use}

The rates of women exposed to breast milk substitute marketing activities were low. Only three percent of women received any type of infant formula for free, and less than one percent received promotional pacifiers, bottles or booklets advertising infant formula.

Still, 42.3 percent of mothers did feed their babies breast milk substitutes or other supplementary foods. Formulas imported from Western countries, such as Nestle, were the most popular (see Table 10). Only about four percent of children still received non-adapted milk products from traditional communist milk kitchens.

Table 10. Breast Milk Substitutes Children Received

\begin{tabular}{|c|c|}
\hline & $\%$ of children \\
\hline Non-adapted milk products from milk kitchens & 3.5 \\
\hline Breast milk substitutes from CIS countries & 14.0 \\
\hline Malysh & 8.5 \\
\hline Maliutka & 3.6 \\
\hline Detolact & 0.2 \\
\hline Other & 1.7 \\
\hline Breast milk substitutes from Western countries & 23.6 \\
\hline Nestle & 14.2 \\
\hline Nutricia & 1.4 \\
\hline Heints & 1.0 \\
\hline Other & 7.1 \\
\hline
\end{tabular}

Overall, four in ten children received infant formula or other supplementary foods after breastfeeding. Generally this practice should be considered correct use, because in this case supplementary feeding should not decrease suckling of breasts and breast milk production. A large proportion of children received supplementary feeding between feedings by breast (74\%), and some children $(6.5 \%)$ received food products before breastfeeding. This practice of using supplementary foods is less desirable because children may become full before feeding by breast, decreasing suckling and breast milk production. 


\section{CONCLUSIONS, RECOMMENDATIONS AND UTILIZATION}

Nutritional and psychological benefits of the method have been well documented and LAM is recommended by the Bellagio Consensus of experts. Rooming the mother and child together in the maternity ward and attaching the infant to the mother's breast within a half hour after birth promotes mother-child bonding early on, in addition to enabling the mother to feed on demand.

Results show that the PLAMIT interventions in both certified Baby-Friendly Hospitals and ordinary hospitals increased women's knowledge and practice of LAM. Taking advantage of women's willingness to breastfeed their children as an option for pregnancy prevention is an excellent opportunity to reduce the rate of unintended pregnancies and repeat abortions in Kazakhstan. According to national DHS statistics, 99 percent of Kazakhstani women breastfed their infants in 1999. Training doctors to provide their clients the information necessary to successfully follow the conditions for LAM, with little effort, provides women a natural way of controlling their fertility.

Breastfeeding rates and knowledge were generally higher among women who delivered at certified Baby-Friendly Hospitals than their counterparts who attended non-certified ordinary hospitals. This evidence highlights the strength of the BFHI's certification process, and suggests that efforts should be made to continue scaling-up this program throughout the Republic. Results also show, however, that improved Lactation Management and Lactational Amenorrhea Method training for hospital staff increased LAM knowledge and practice among BFH clients already practicing breastfeeding.

The study results reveal that the policy and practice of certified BFHs by themselves positively influence use of the birth spacing effect of breastfeeding in comparison with non-certified ordinary hospitals. Following the study's end, the Ten Steps for Successful Breastfeeding were promoted in all ordinary hospitals participating in the study and further certification of these hospitals as Baby-Friendly is planned for the next two years.

The results of the study show that the intervention positively influenced knowledge and attitudes with regard to LAM's birth spacing effects among women who delivered in both certified BFHs and ordinary hospitals. The recommendation for strengthening the training of medical personnel on LAM use and counseling is being implemented in BFHs and ordinary hospitals via the Ministry of Health and the National Working Group on Breastfeeding. The intervention has been introduced to other sites via education of health personnel from all the regions (Oblasts) in Kazakhstan. The LAM training program for physicians is incorporated into the curriculum of the permanent course on breastfeeding at the Postgraduate Training Institute for Doctors in Kazakhstan. An average of ten physicians are trained every month at this course. After returning to their permanent place of work, physicians then train their colleagues.

The results of the study will also be used to improve the program and influence policy on breastfeeding and LAM use in Kazakhstan in the following ways:

1) The results of the study will be presented and discussed in seminars and workshops at the country and the Region of Central Asian Republics levels, and will be published in 
professional journals.

2) On the basis of the results of the study, recommendations on breastfeeding and LAM use for medical personnel and pregnant and lactating women will be elaborated and implemented.

3 ) National-wide communication activities on breastfeeding and LAM use will be implemented via the mass media.

4 ) The results of the study on breastfeeding and LAM use will be integrated into the curriculum of the Medical University and Doctors' Advanced Training Institute in Almaty.

A new grant application for funding implementation of the study recommendations into practice in Kazakhstan was prepared and submitted following the WHO and FRONTIERS course on Operations Research in Reproductive Health that took place in Almaty, Kazakhstan, April 14 25, 2003. A funding decision is expected in 2004. 


\section{BIBLIOGRAPHY}

Bender, D.E., E. Dusch, M.F. McCann. 1998. From efficacy to effectiveness: selecting indicators for a community-based lactational amenorrhoea method promotion programme. J. Biosoc. Sci: v. 30(2), p. 193-225. Review.

Bracher M. 1992. Breastfeeding, lactational infertility, contraception and the spacing of births: Implications of the Bellagio Consensus Statement. Health Transition Review: v. 2, p. 19-47.

Cooney K. 1996. Assessment of the nine-month Lactational Amenorrhea Method in Rwanda (MAMA-9). Studies in Family Planning: v. 27, p. 162-171.

Diaz S., M. Seron-Ferre, H.B. Croxatto, J. Veldhuis. 1995. Neuroendocrine mechanisms of lactational infertility in women. Biological Research: v. 28, p. 155-163.

Family Health International. 1988. Consensus statement: Breastfeeding as a family planning method. Lancet: v. 8621, p. 1204-1205.

Hardy, E., L.C. Santos, M.J. Osis, G. Carvalho, J.G. Cecatti, A. Faundes. 1998. Contraceptive use and pregnancy before and after introducing lactational amenorrhea (LAM) in a postpartum program. Advances in Contraception: v. 14(1), p. 59-68.

Hight-Laukaran V., M.H. Labbok, A.E. Peterson, V. Fletcher, H. von Hertzen, P.F.A. Van Look. 1997. Multicenter study of the Lactational Amenorrhea Method (LAM): II. Acceptability, utility and policy implications. Contraception: v. 55(6), p. 337-346.

Kazi A., K.I. Kennedy, C.M. Visness, T. Khan. 1995. Effectiveness of the Lactation Amenorrhea Method in Pakistan. Fertility and Sterility: v. 64, p. 717-723.

Kennedy, K.I. and M. Kotelchuck. 1998. Policy Considerations for the Introduction and Promotion of the Lactational Amenorrhea Method: Advantages and Disadvantages of LAM. J. Hum. Lact: v. 14 (3), p. 191-203.

Kennedy, K.I., M. Kotelchuck, C.M. Visness et al. 1998. Users' understanding of the lactational amenorrhea method and the occurrence of pregnancy. J. Hum. Lact: v. 14(3) p. 209-18

Kennedy, K.I., M.H. Labbok, P.F.A. Van Look. 1996. Consensus Statement: Lactational Amenorrhea Method for family planning. International Journal of Gynecology and Obstetrics: v. 54, p. 55-57.

Kennedy, K.I., K. Cooney, S. Coly. 1994. Guidelines for breastfeeding and the Lactational Amenorrhea Method (3rd ed.). Washington, DC: Institute for Reproductive Health.

Kennedy, K.I. and C.M. Visness. 1992. Contraceptive efficacy of lactational amenorrhea. Lancet, v. 339, p. 227-230.

Kennedy, K.I., R. Rivera, A. McNeilly. 1989. Consensus statement on the use of breastfeeding as a family planning method. Contraception: v. 39, p. 477-496.

Labbok, M.H., V. Hight-Laukaran, A.E. Peterson, V. Fletcher, H. von Hertzen, P.F.A. Van Look. 1997. Multicenter study of the Lactational Amenorrhea Method (LAM): Efficacy, duration and implication for clinical application. Contraception, v. 55(6), p. 327-336.

Marston, Cicely and John Cleland. 2003. Relationships Between Contraception and Abortion: A Review of the Evidence. International Family Planning Perspectives, 29(1): 6-13

Promotion of Lactation Amenorrhea Method Intervention Trial (PLAMIT) 
McNeilly, A.S. 1997. Lactation and Fertility. Journal of Mammary Gland Biology and Neoplasia: v. 2, p. 291-298.

McNeilly, A.S. 1994. Suckling and the control of gonadotropin secretion. In: Knobil E., Neil J. eds. The Physiology of Reproduction, 2nd ed., p. 1179-1212. New York: Raven.

McNeilly, A.S., C.C.K. Tay, A. Glasier. 1994. Physiological mechanisms underlying lactational amenorrhea. In: Human Reproductive Ecology: Interactions of Environment, Fertility, and Behavior. Annals of the New York Academy of Sciences: p. 145-155.

McNeilly, A.S. 1993. Breastfeeding and fertility. In: Gray R., H. Leridon, S. Spira, eds. Biomedical and Demographic Determinants of Reproduction, p. 391-412. Oxford, England: Clarendon.

National Institute of Nutrition, Kazakhstan, Academy of Preventive Medicine, Kazakhstan and Macro International Inc., USA. 1996. National Demographic and Health Survey in Kazakhstan, 1995. Calverton, Maryland.

Perez, A., M.H. Labbok, J.T. Queenan. 1992. Clinical study of the Lactational Amenorrhea Method for family planning. Lancet: v. 339, p. 968-970.

Ramos, Rebecca, K.I. Kennedy, and C.M. Visness. Effectiveness of lactational amenorrhoea in prevention of pregnancy in Manila, the Philippines: non-comparative prospective trial. 1996.

British Medical Journal: v. 313, p. 909-912.

Serbanescu, Florina. 2004. "Recent Abortion and Contraception Dynamics in Eastern Europe." Psychosocial Workshop at Population Association of America Annual Meeting.

Short, R.V., P.R. Lewis, M.B. Renfree et al. 1991. Contraceptive effects of extended periods of lactational amenorrhea: Beyond the Bellagio Consensus. Lancet: v. 337, p. 715-717.

Tay, C.C.K. 1991. Mechanisms controlling lactational infertility. J. Hum. Lact.: v. 7, p. 15-18.

Trussell, J. and G. Santow. 1991. Is the Bellagio consensus statement on the use of contraception sound public-health policy? Health Transition Review: v. 1, p. 105-107.

Vekemans, M. 1997. Postpartum contraception: the lactational amenorrhea method. Eur. J. Contracept. Reprod. Health. Care: v. 2(2), p. 105-111. Review.

Wade, K.B., F. Sevilla, M.H. Labbok. 1994. Integrating the Lactational Amenorrhea Method into a family planning program in Ecuador. Studies in Family Planning: v. 25, p. 162-175.

Weis, P. 1993. The contraceptive potential of breastfeeding in Bangladesh. Studies in Family Planning: v. 24, p. 100-108.

Westoff, C.F. 2000. The Substitution of Contraception for Abortion in Kazakhstan in the 1990s, DHS Analytical Studies, Calverton, MD, USA: Macro International, 2000, No 1.

World Health Organization Task Force on Methods for the Natural Regulation of Fertility. 1999. The World Health Organization multinational study of breast-feeding and lactational amenorrhea. III. Pregnancy during breast-feeding. Fertil Steril., v. 72 (3), p. 431-440.

World Health Organization Task Force on Methods for the Natural Regulation of Fertility. 1999. The World Health Organization multinational study of breast-feeding and lactational amenorrhea. IV. Postpartum bleeding and lochia in breast-feeding women. Fertil Steril., 1999 Sep.: v. 72 (3), p. 441-447.

Promotion of Lactation Amenorrhea Method Intervention Trial (PLAMIT) 
World Health Organization. 1981. International Code of Marketing of Breastmilk Substitutes. WHO: Geneva. 